\title{
Formation of ultrathin cobalt ferrite films by interdiffusion of $\mathrm{Fe}_{3} \mathrm{O}_{4} / \mathrm{CoO}$ bilayers
}

\author{
J. Rodewald $\odot,{ }^{1}$ J. Thien, ${ }^{1}$ T. Pohlmann, ${ }^{1,2}$ M. Hoppe,${ }^{1,2}$ F. Timmer, ${ }^{1}$ F. Bertram, ${ }^{2}$ K. Kuepper, ${ }^{1}$ and J. Wollschläger ${ }^{1}$ \\ ${ }^{1}$ Department of Physics, Osnabrück University, Barbarastraße 7, D-49076 Osnabrück, Germany \\ ${ }^{2}$ DESY, Photon Science, Notkestraße 85, D-22607 Hamburg, Germany
}

(Received 18 April 2019; revised manuscript received 6 September 2019; published 16 October 2019)

\begin{abstract}
In this work an alternate pathway is demonstrated to form ultrathin cobalt ferrite $\left(\mathrm{Co}_{x} \mathrm{Fe}_{3-x} \mathrm{O}_{4}\right)$ films by interdiffusion of $\mathrm{Fe}_{3} \mathrm{O}_{4} / \mathrm{CoO}$ bilayers. Bilayer samples with different $\mathrm{Fe}_{3} \mathrm{O}_{4} / \mathrm{CoO}$ thickness ratios have been prepared by reactive molecular beam epitaxy on $\mathrm{Nb}$-doped $\mathrm{SrTiO}_{3}(001)$ substrates to obtain cobalt ferrite films of varied stoichiometry. Subsequently, oxygen-assisted postdeposition annealing experiments for consecutive temperature steps between $300^{\circ} \mathrm{C}$ and $600{ }^{\circ} \mathrm{C}$ have been conducted monitoring the interdiffusion process by means of high-resolution $\mathrm{x}$-ray reflectivity, soft and angle-resolved hard x-ray photoelectron, and $\mathrm{x}$-ray absorption spectroscopy. Magnetic properties were characterized using superconducting quantum interference device magnetometry. The interdiffusion process starts from $300{ }^{\circ} \mathrm{C}$ annealing temperature and is completed for temperatures above $500^{\circ} \mathrm{C}$. For completely interdiffused films with Co:Fe ratios larger than 0.84:2 a thin segregated $\mathrm{CoO}$ layer on top of the ferrite is formed. This $\mathrm{CoO}$ segregation is attributed to surface and interface effects. In addition, multiplet calculations of x-ray absorption spectra are performed to determine the occupancy of different sublattices. These results are correlated with the magnetic properties of the ferrite films. A stoichiometric $\mathrm{CoFe}_{2} \mathrm{O}_{4}$ film with partial inversion has been formed exhibiting homogeneously distributed $\mathrm{Co}^{2+}$ and mainly $\mathrm{Fe}^{3+}$ valence states if the initial $\mathrm{Co}: \mathrm{Fe}$ content is 1.09:2. Thus, for the formation of stoichiometric cobalt ferrite by the proposed postdeposition annealing technique an initial Co excess has to be provided as the formation of a top $\mathrm{CoO}$ layer is inevitable.
\end{abstract}

DOI: 10.1103/PhysRevB.100.155418

\section{INTRODUCTION}

Transition metal ferrites with (inverse) spinel structure are in the focus of current research due to a number of intriguing properties, including high Curie temperatures and significant magnetic saturation moments [1]. These features stemming from a ferrimagnetic ground state make ferrites potential candidates for a number of applications in spintronics [2-4], spincaloritronics [5], but also in the fields of electrocatalysis [6,7], as supercapacitors [8], and even as high-capacity anode material in lithium ion batteries $[9,10]$.

In the field of spintronics, the capability of generating highly spin-polarized electron currents determines the quality of operation of spin-based devices. For this purpose, inverse spinel ferrites like $\mathrm{NiFe}_{2} \mathrm{O}_{4}$ (NFO) and $\mathrm{CoFe}_{2} \mathrm{O}_{4}$ (CFO) are suitable for spin filter applications [11-14]. Due to their insulating and ferrimagnetic properties these ferrites exhibit an exchange splitting of the energy levels in the conduction band leading to different tunneling probabilities for the two spin orientations and making them highly suited as spin filters [4]. In particular, room-temperature spin filtering has only been obtained for CFO-based junctions, exhibiting a spin-polarization value of $-8 \%$ [12]. Since the spin-tunneling probability decreases exponentially with increasing tunneling barrier thickness, ferrites have to be prepared as thin films with low interface roughness if high-quality spin filters are aimed for.

In $\mathrm{CoFe}_{2} \mathrm{O}_{4}$, as an ideal cubic inverse spinel, $\mathrm{Co}^{2+}$ cations occupy octahedrally coordinated $\left(O_{h}\right)$ lattice sites in the fcc oxygen sublattice, while $\mathrm{Fe}^{3+}$ cations are equally distributed across both octahedral and tetrahedral $\left(T_{d}\right)$ sites. In contrast, in a normal spinel the divalent cations only occupy $T_{d}$ sites, whereas trivalent cations are arranged on $O_{h}$ sites. Intermediate states between normal and inverse spinels can be characterized by a degree of inversion $\gamma$, which is the fraction of divalent cations occupying octahedral sites. The cationic order of ferrites can therefore be described by

$$
\left[\mathrm{TM}_{1-\gamma}^{2+} \mathrm{Fe}_{\gamma}^{3+}\right]_{T_{d}}\left[\mathrm{TM}_{\gamma}^{2+} \mathrm{Fe}_{2-\gamma}^{3+}\right]_{O_{h}} \mathrm{O}_{4}
$$

with divalent transition metal cations TM ( $\mathrm{Fe}, \mathrm{Co}, \mathrm{Ni}$, etc.). The degree of inversion can attain values between $\gamma=0$ for a normal spinel and $\gamma=1$ for complete inversion. Therefore, $\gamma$ is an essential parameter for the description of cationic order, since the distribution of cations affects most properties of the ferrites. For instance, magnetic ordering is dominated by oxygen-mediated superexchange interaction between $T_{d}$ and $O_{h}$-coordinated $\mathrm{Fe}^{3+}$ cations on two antiferromagnetically coupled sublattices as well as oxygen-mediated doubleexchange interaction of $\mathrm{Fe}^{3+}$ and $\mathrm{TM}^{2+}$ cations on $O_{h}$ sites with ferromagnetic coupling.

Most commonly, $\mathrm{MgO}(001)$ substrates are used as substrates for the preparation of thin ferrite films, since the lattice mismatch between, i.e., $\mathrm{CoFe}_{2} \mathrm{O}_{4}$ (lattice constant $a_{\mathrm{CFO}}=$ $0.8392 \mathrm{~nm})$ and $\mathrm{MgO}(001)\left(a_{\mathrm{MgO}}=0.4212 \mathrm{~nm}\right)$ is only $0.4 \%$ (comparing the doubled lattice constant of $\mathrm{MgO}$ with one lattice distance of $\mathrm{CFO}$ ). However, $\mathrm{Mg}^{2+}$ diffusion into ferrite films has been reported for substrate temperatures above $250^{\circ} \mathrm{C}$ [15]. This interdiffusion process through a $\mathrm{Fe}_{3} \mathrm{O}_{4}$ layer has been studied in detail $[16,17]$, having significant impact 
on interface roughness and antiphase boundaries, which limits the performance of ferrite thin film spin filters. One way to prevent interdiffusion between substrate and film is to use other more stable substrates. For instance, $\mathrm{SrTiO}_{3}(001)$ shows no interdiffusion with thin ferrite films even for higher annealing temperatures [18] and is therefore used as substrate in this work.

For most studies, thin ferrite films are prepared by sputter deposition [11,19], pulsed laser deposition [20], molecular beam epitaxy [21], or chemical solution deposition [22]. Here, we investigate an alternate pathway to form $\mathrm{CoFe}_{2} \mathrm{O}_{4}$ thin films by depositing a $\mathrm{Fe}_{3} \mathrm{O}_{4} / \mathrm{CoO}$ bilayer stack on $\mathrm{Nb}: \mathrm{SrTiO}_{3}(001)$ using reactive molecular beam epitaxy. In order to form $\mathrm{Co}_{x} \mathrm{Fe}_{3-x} \mathrm{O}_{4}(x \leqslant 1)$ films the prepared bilayers are interdiffused by postdeposition annealing (PDA) in a diluted oxygen atmosphere.

For potential applications, knowledge about fundamental chemical and structural properties during the interdiffusion process is indispensable. For this purpose, three prepared samples (samples A, B, and $\mathrm{C}$ ) with different $\mathrm{Fe}_{3} \mathrm{O}_{4} / \mathrm{CoO}$ thickness ratios have been annealed subsequently for temperatures between $300^{\circ} \mathrm{C}$ and $600^{\circ} \mathrm{C}$ after deposition. The film structure and chemical properties of the annealed bilayer system has been studied by means of high-resolution $\mathrm{x}$-ray reflectivity (XRR) and soft/hard x-ray photoelectron (XPS/HAXPES) and x-ray absorption spectroscopy (XAS), respectively. X-ray absorption spectra have been analyzed with respect to the occupancy of different sites calculating spectra based on multiplet theory. Magnetic properties before and after PDA treatment have been characterized using superconducting quantum interference device (SQUID) magnetometry. In detail, the saturation magnetization has been compared to the magnetization calculated from the occupancy of different sublattices obtained from XAS.

\section{EXPERIMENTAL DETAILS}

$\mathrm{Fe}_{3} \mathrm{O}_{4} / \mathrm{CoO}$ bilayers with different thicknesses have been prepared on conductive 0.05 wt \% $\mathrm{Nb}$ doped $\mathrm{SrTiO}_{3}(001)$ substrates by reactive molecular beam epitaxy in a multichamber ultrahigh-vacuum system. The substrates have been cleaned by annealing at $400{ }^{\circ} \mathrm{C}$ for $1 \mathrm{~h}$ in a molecular oxygen atmosphere of $1 \times 10^{-4}$ mbar prior to film deposition. The chemical cleanness and crystallinity of the surface was controlled in situ by x-ray photoelectron spectroscopy (XPS) and low energy electron diffraction (LEED), respectively. Both oxide layers have been deposited by thermal evaporation of the metals from pure rods in a diluted molecular oxygen atmosphere. For $\mathrm{CoO}$ films the substrates were held at $435^{\circ} \mathrm{C}$ and the oxygen pressure was kept at $1 \times 10^{-5}$ mbar, while $\mathrm{Fe}_{3} \mathrm{O}_{4}$ films were grown on top at $350^{\circ} \mathrm{C}$ and $5 \times 10^{-6}$ mbar $\mathrm{O}_{2}$ pressure to ensure optimal growth conditions. Stoichiometry and good crystallinity of the respective film surfaces were again confirmed by XPS and LEED, respectively.

The samples were transported under ambient conditions to the Diamond Light Source (DLS) synchrotron and to PETRA III of the Deutsches Elektronen-Synchrotron (DESY), where the effects of annealing the bilayer system were investigated. Therefore, each sample was annealed in four consecutive
TABLE I. Values for the IMFP $\lambda$ and information depth $D_{I}^{95}$ in soft XPS $(h v=1100 \mathrm{eV})$ and HAXPES $(h v=5948 \mathrm{eV})$ measurements for photoelectrons originating from $\mathrm{Fe} 2 p$ and $\mathrm{Co} 2 p$ orbitals passing through $\mathrm{CoFe}_{2} \mathrm{O}_{4}$.

\begin{tabular}{lcccccc}
\hline \hline & \multicolumn{2}{c}{ Soft XPS } & & \multicolumn{3}{c}{ HAXPES } \\
\cline { 2 - 3 } \cline { 5 - 6 } \cline { 5 - 6 } & $\lambda$ & $D_{I}^{95}\left(\phi=0^{\circ}\right)$ & & $\lambda$ & $D_{I}^{95}\left(\phi=0^{\circ}\right)$ & $D_{I}^{95}\left(\phi=60^{\circ}\right)$ \\
\hline Fe $2 p$ & $1.0 \mathrm{~nm}$ & $3.0 \mathrm{~nm}$ & & $7.4 \mathrm{~nm}$ & $22.2 \mathrm{~nm}$ & $11.1 \mathrm{~nm}$ \\
Co $2 p$ & $0.9 \mathrm{~nm}$ & $2.7 \mathrm{~nm}$ & & $7.3 \mathrm{~nm}$ & $21.9 \mathrm{~nm}$ & $10.9 \mathrm{~nm}$ \\
\hline \hline
\end{tabular}

steps to $300^{\circ} \mathrm{C}, 400^{\circ} \mathrm{C}, 500^{\circ} \mathrm{C}$, and $600^{\circ} \mathrm{C}$ for $30 \mathrm{~min}$ in an oxygen atmosphere of $5 \times 10^{-6} \mathrm{mbar}$, which was applied to avoid reduction of the films. At beamlines I09 of DLS and P09 of DESY the depth-dependent composition was analyzed by high-resolution angle-resolved hard x-ray photoelectron spectroscopy (AR-HAXPES). Additional soft XPS measurements performed at DLS reveal information about the nearsurface film composition. For HAXPES an x-ray energy of $h v=5930 \mathrm{eV}$ at DLS and $h v=5948 \mathrm{eV}$ at PETRA III was used to create photoelectrons with high kinetic energy and, thus, a significantly higher probing depth than for soft XPS measurements $(h v=1100 \mathrm{eV})$.

The information depth $D_{I}^{95}$, from which $95 \%$ of the photoelectrons originate, is defined by

$$
D_{I}^{95}(\phi)=-\lambda \cos \phi \ln (1-95 / 100),
$$

where $\lambda$ is the inelastic mean-free path (IMFP) and $\phi$ the offnormal emission angle of photoelectrons. Photoelectron spectra were recorded for different photoemission angles $\phi$, using a two-dimensional VG Scienta EW4000 electron analyzer with $\pm 30^{\circ}$ angular acceptance at beamline I09. At beamline P09 a SPECS Phoibos $225 \mathrm{HV}$ hemispherical analyzer with a delay-line detector and a wide-angle lens $\left( \pm 30^{\circ}\right.$ angular acceptance) is used. The IMFP $\lambda$ was determined by using the Tanuma, Powell, and Penn algorithm (TPP-2M) formula [23]. For comparison, calculated values for $\lambda$ and $D_{I}^{95}$ in soft $x$-ray photoemission and HAXPES measurements are listed in Table I regarding photoelectrons originating from $\mathrm{Fe} 2 p$ and Co $2 p$ orbitals. By comparison of the maximum information depth $\left(\phi=0^{\circ}\right)$ in soft XPS and HAXPES, the surface and bulk sensitivities of each technique become obvious. For the maximum off-normal detection angle of $\phi=60^{\circ}$ in HAXPES measurements the information depth is halved compared to perpendicular photoemission. All HAXPES spectra were recorded in angular mode with off-normal photoemission angles between $0^{\circ}$ and $60^{\circ}$ summing up data within an acceptance angle of $8^{\circ}$ due to better statistics.

Complementary $\mathrm{x}$-ray absorption spectroscopy measurements were performed at beamline I09 at DLS. For this purpose the x-ray energy of the incoming beam was tuned in the soft $\mathrm{x}$-ray regime over the $\mathrm{Fe}$ and $\mathrm{Co} L_{2,3}$ edges (700-740 eV and 770-810 eV, respectively). The absorption signal was detected in surface-sensitive total electron yield (TEY) mode, which provides probing depths of $2-5 \mathrm{~nm}$ in transition metal oxides [24-26]. All presented XAS measurements have been normalized to the current from an Au-coated mesh in the incident $\mathrm{x}$-ray beam. Furthermore, the spectra 
TABLE II. Film thicknesses of the bottom CoO layer $\left(d_{\mathrm{CoO}}^{\text {bot }}\right)$, the ferrite film $\left(d_{\text {ferrite }}\right)$, and the segregated top CoO layer $\left(d_{\mathrm{CoO}}^{\text {top }}\right)$ for all three samples before thermal treatment and after the last annealing step of $600{ }^{\circ} \mathrm{C}$.

\begin{tabular}{|c|c|c|c|c|c|c|}
\hline & \multicolumn{2}{|c|}{ Sample A } & \multicolumn{2}{|c|}{ Sample B } & \multicolumn{2}{|c|}{ Sample C } \\
\hline & as prepared & $T=600^{\circ} \mathrm{C}$ & as prepared & $T=600^{\circ} \mathrm{C}$ & as prepared & $T=600^{\circ} \mathrm{C}$ \\
\hline$d_{\mathrm{CoO}}^{\mathrm{top}}$ & & $0.8 \mathrm{~nm}$ & & $0.7 \mathrm{~nm}$ & & \\
\hline $\begin{array}{l}d_{\text {ferrite }} \\
d_{\mathrm{CoO}}^{\text {bot }}\end{array}$ & $\begin{array}{c}13.9 \mathrm{~nm} \\
6.0 \mathrm{~nm}\end{array}$ & $18.7 \mathrm{~nm}$ & $\begin{array}{l}11.5 \mathrm{~nm} \\
3.8 \mathrm{~nm}\end{array}$ & $14.2 \mathrm{~nm}$ & $\begin{array}{c}22.1 \mathrm{~nm} \\
2.5 \mathrm{~nm}\end{array}$ & $25.0 \mathrm{~nm}$ \\
\hline
\end{tabular}

have been shifted by a beamline specific energy offset, which was determined by measuring the Fermi edge of a clean $\mathrm{Au}$ foil in HAXPES.

In order to quantify the cationic distribution with different occupancies in the (inverse) spinel structure of the ferrite layer, charge transfer multiplet (CTM) calculations were performed and compared to the experimental XAS data. In these calculations a molecule complex is taken as a basis, composed of a respective cation in a given ligand crystal field considering charge transfer between cation and ligand. In the case of $\mathrm{Co}_{x} \mathrm{Fe}_{3-x} \mathrm{O}_{4}, \mathrm{Fe}^{2+}, \mathrm{Fe}^{3+}$, and $\mathrm{Co}^{2+}$ cations can each be coordinated in octahedral or tetrahedral oxygen ligand fields. The total CTM spectrum is obtained by a weighted linear superposition of the individual spectra of each cationic state. By comparison of the calculation with the experimental XAS spectra, quantitative information about the site occupancies of each cation is determined. In addition to crystal field effects and charge transfer interaction, the CTM model includes $100 \%$ spin-orbit coupling and reduction of the Slater integrals $F(d d), F(p d)$, and $G(p d)$ to account for $d-d$ and $p$ - $d$ Coulomb and exchange interactions [27]. $F(d d), F(p d)$, and $G(p d)$ were each reduced to $80 \%$, which is consistent within $\pm 10 \%$ with previous studies on $\mathrm{Fe}_{3} \mathrm{O}_{4}$ and $\mathrm{CoFe}_{2} \mathrm{O}_{4}$ [28-34]. All spectra are broadened by a Lorentzian with a half-width of $0.2 \mathrm{eV}(0.45 \mathrm{eV})$ for $L_{3}\left(L_{2}\right)$ edges to account for core-hole lifetime broadening and by a Gaussian with a half-width of $0.25 \mathrm{eV}$ to account for instrumental broadening. Charge transfer is considered by setting the $\mathrm{O} 2 p-\mathrm{Fe} 3 d$ charge transfer energy $\Delta$ as well as the difference $U_{p d}-U_{d d}$ of the monopole parts of $2 p-3 d$ and $3 d-3 d$ Coulomb interactions [35]. The best results were obtained for $\Delta=6.0 \mathrm{eV}$ and $U_{p d}-U_{d d}=1.0 \mathrm{eV}$ for all cations, which is consistent with values used in former studies on $\mathrm{Fe}_{3} \mathrm{O}_{4}[32,35]$.

Additional x-ray reflectivity (XRR) experiments were conducted at beamline I07 of DLS with an X-ray energy of $20 \mathrm{keV}$ to investigate film thicknesses after each annealing step. For this purpose, the samples were cut into two pieces prior to investigations at DLS/PETRA III, one piece used for HAXPES/XPS/XAS and one for XRR measurements. XRR data were analyzed using an in-house-developed fitting tool based on the Parratt algorithm [36] and Névot-Croce roughness model [37].

In total, three samples with different $\mathrm{Co}: \mathrm{Fe}$ ratios and comparable total bilayer thicknesses between 15 and $25 \mathrm{~nm}$ have been investigated. The initial film thicknesses of all three samples are listed in Table II. From these thicknesses we obtain initial Co:Fe ratios of 1.09:2, 0.84:2, and 0.28:2 for samples A, B, and C, respectively.

\section{RESULTS}

\section{A. XRR}

X-ray reflectivity curves with corresponding calculated data after each annealing step for sample A are depicted in Fig. 1, serving as a representative for all three samples. Data of samples B and C are shown in the Supplemental Material [38]. The corresponding layer models used to fit the reflectivity data for the as-prepared sample and after annealing at $400{ }^{\circ} \mathrm{C}$ and $600{ }^{\circ} \mathrm{C}$ are shown in the insets of Fig. 1.

The XRR data for sample A before and after annealing at $300{ }^{\circ} \mathrm{C}$ show clear narrow intensity oscillations accompanied by a broad but weaker second oscillation causing a beating effect of the reflectivity and pointing to a bilayer structure with smooth interfaces. The reflectivity curves of the as-prepared sample can be fitted by a basic bilayer model, consisting of a $\mathrm{Fe}_{3} \mathrm{O}_{4}$ film on top of a $\mathrm{CoO}$ layer on a $\mathrm{SrTiO}_{3}$ substrate. After annealing at $300{ }^{\circ} \mathrm{C}$ the data can be described assuming a bilayer model with a slightly thinner $\mathrm{CoO}$ layer underneath a rather thicker ferrite-like layer compared to the as-prepared sample. For further annealing above $400{ }^{\circ} \mathrm{C}$ this simple bilayer model is not sufficient to describe the measured reflectivity data properly. Instead, a very thin $\mathrm{CoO}$ film as a third layer on top of the double-layered system has to be added. In addition, the ferrite-like film grows in thickness while the subjacent $\mathrm{CoO}$ film becomes significantly thinner and the

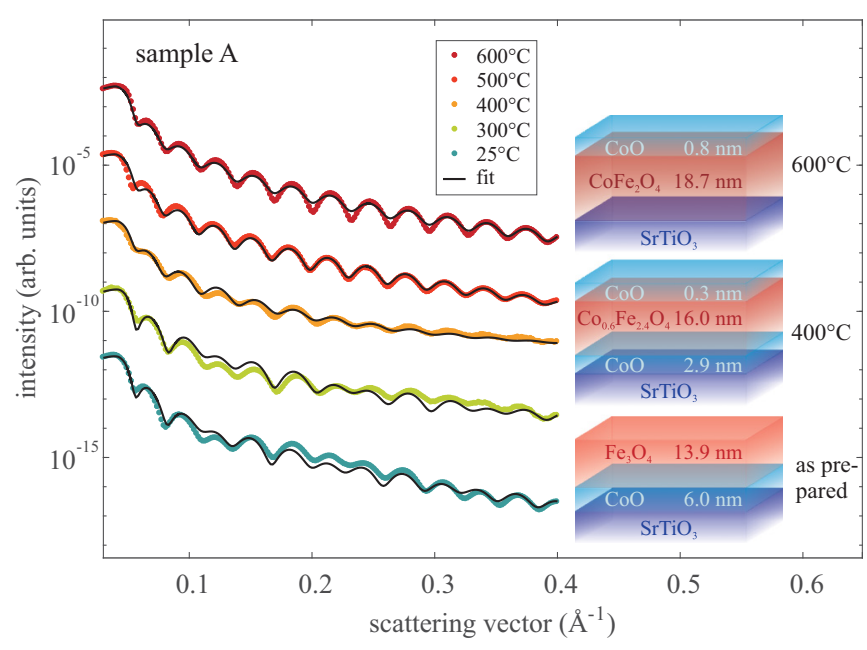

FIG. 1. Reflectivity curves of sample A for the different annealing steps with respective simulation. The underlying film models, which describe the data before thermal treatment and after annealing at $400{ }^{\circ} \mathrm{C}$ and $600^{\circ} \mathrm{C}$, are displayed in the insets. 
(a)

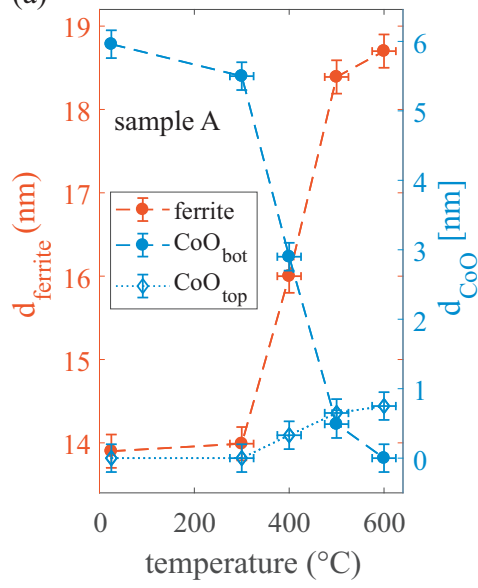

(b)

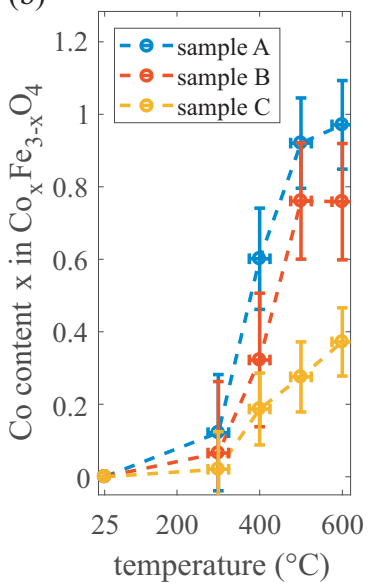

FIG. 2. (a) Film thicknesses dependent on annealing temperature for sample A. (b) Co content $x$ of the $\mathrm{Co}_{x} \mathrm{Fe}_{3-x} \mathrm{O}_{4}$ films in samples $\mathrm{A}, \mathrm{B}$, and $\mathrm{C}$ at different temperatures determined from XRR results.

interface roughness between these two films increases, causing a damping of the oscillations at higher scattering vectors. These observations can be explained by an interdiffusion of $\mathrm{CoO}$ and $\mathrm{Fe}_{3} \mathrm{O}_{4}$ and the formation of a $\mathrm{Co}_{x} \mathrm{Fe}_{3-x} \mathrm{O}_{4}$ film in between two $\mathrm{CoO}$ layers. The very thin topmost $\mathrm{CoO}$ layer is assumed to be segregated from the initial underlying $\mathrm{CoO}$ layer through the ferrite-like film as it has already been observed for the interdiffusion of $\mathrm{NiO}$ and $\mathrm{Fe}_{3} \mathrm{O}_{4}$ thin films [18]. After the last annealing step of $600^{\circ} \mathrm{C}$ the XRR data are again described best by a bilayer model consisting of the $\mathrm{Co}_{x} \mathrm{Fe}_{3-x} \mathrm{O}_{4}$ film and the segregated $\mathrm{CoO}$ film on top. The initial $\mathrm{CoO}$ film dissolved completely and interdiffused into the ferrite-like film resulting in increased oscillations meaning lower interface roughnesses. The evolution of film thicknesses determined by analysis of the reflectivity data of the bottom and the top $\mathrm{CoO}$ layer and the ferrite-like $\mathrm{Co}_{x} \mathrm{Fe}_{3-x} \mathrm{O}_{4}$ film dependent on the annealing temperature is depicted in Fig. 2(a) exemplarily for sample A.

Table II gives an overview of the XRR results for the as-prepared bilayer system and the film stack after the last annealing step of $600^{\circ} \mathrm{C}$ for all three samples. One can see that for all samples the initial subjacent $\mathrm{CoO}$ film completely dissolved by interdiffusion with the overlying $\mathrm{Fe}_{3} \mathrm{O}_{4}$ layer and segregation to the top after annealing at $600^{\circ} \mathrm{C}$. Only sample $\mathrm{C}$ with a very thin initial $2.5 \mathrm{~nm} \mathrm{CoO}$ film compared to the initial $22.1 \mathrm{~nm} \mathrm{Fe}_{3} \mathrm{O}_{4}$ layer on top does not exhibit a segregated $\mathrm{CoO}$ film after annealing.

Taking into account the shrinking initial $\mathrm{CoO}$ layer as well as the arising and growing segregated $\mathrm{CoO}$ layer on top, one can determine the amount of $\mathrm{CoO}$ incorporated into the initial $\mathrm{Fe}_{3} \mathrm{O}_{4}$ layer to form a Co ferrite film. Assuming a homogeneously interdiffused $\mathrm{Co}_{x} \mathrm{Fe}_{3-x} \mathrm{O}_{4}$ film after each annealing step, we determined the Co amount $x$ in the ferrite films for samples A, B, and C [cf. Fig. 2(b)]. The Co amount starts to rise in the ferrite-like film at $300^{\circ} \mathrm{C}$ and is increasing at each annealing step up to $600^{\circ} \mathrm{C}$. Samples B and C exhibit lower Co amounts, with values of up to $x_{B}=0.76$ and $x_{C}=0.37$, respectively, than are needed for stoichiometric $\mathrm{CoFe}_{2} \mathrm{O}_{4}$. Only sample A with a value of $x_{A}=0.98$ at $600{ }^{\circ} \mathrm{C}$

(a)

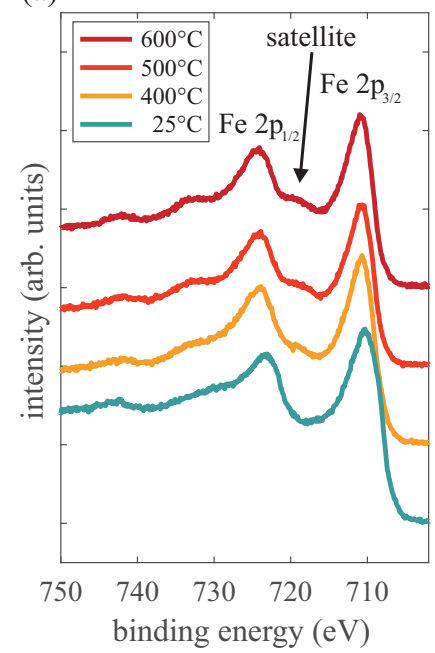

(b)

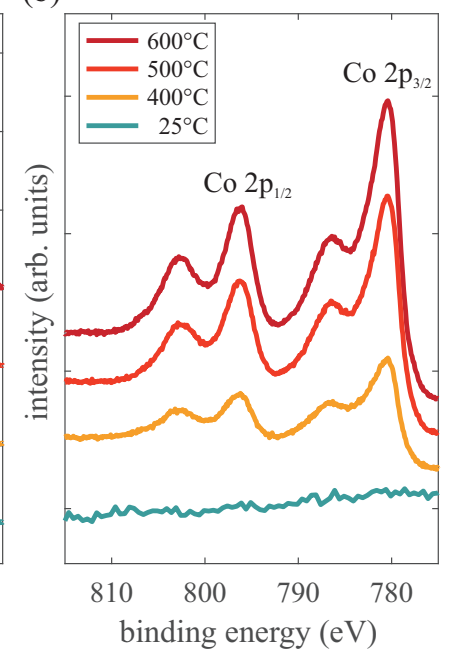

FIG. 3. Soft XPS results of sample A of (a) Fe $2 p$ and (b) Co $2 p$ core-level spectra after annealing at different temperatures.

exhibits a nearly stoichiometric Co:Fe ratio and is therefore assumed to be a stoichiometric homogeneous cobalt ferrite film underneath the top $\mathrm{CoO}$ layer.

\section{B. Soft XPS}

Soft $\mathrm{x}$-ray photoemission provides information about the stoichiometry in the near-surface region due to the low excitation energy and thus small information depth of photoelectrons (cf. Table I).

Figures 3(a) and 3(b) show the soft XPS Fe $2 p$ and Co $2 p$ core-level spectra after transport to DLS under ambient conditions and after each annealing step for sample A. Ahead of thermal treatment, the Fe $2 p$ spectrum for sample A shows no distinguishable $\mathrm{Fe}^{2+}$ or $\mathrm{Fe}^{3+}$ charge-transfer satellites, indicating a mixture of both valence states. In addition, the $\mathrm{Fe} 2 p_{3 / 2}$ and $\mathrm{Fe} 2 p_{1 / 2}$ peak positions at binding energies of 710.5(2) eV and 723.6(2) eV correspond to literature values known for magnetite [39]. These observations confirm a stable $\mathrm{Fe}_{3} \mathrm{O}_{4}$ surface without significant oxidation or reduction during transport under ambient conditions. Furthermore, there is no Co $2 p$ signal detectable for the untreated sample due to the small information depth and high surface sensitivity of soft XPS, showing that there was no diffusion of $\mathrm{CoO}$ to the surface before annealing and indicating a closed $\mathrm{Fe}_{3} \mathrm{O}_{4}$ layer on top of the subjacent $\mathrm{CoO}$ film.

After annealing at $400{ }^{\circ} \mathrm{C}$ the shape of the $\mathrm{Fe} 2 p$ corelevel spectrum changes. A charge-transfer satellite at around 719.0(4) eV appears, which corresponds to a major excess of $\mathrm{Fe}^{3+}$ valence states $[39,40]$. This feature becomes even more pronounced after annealing at temperatures of $500{ }^{\circ} \mathrm{C}$ and $600{ }^{\circ} \mathrm{C}$. From the first annealing step at $400^{\circ} \mathrm{C}$ on, a distinct Co $2 p$ signal is visible demonstrating Co diffusion to the near-surface region. This Co $2 p$ spectrum becomes more intense but does not significantly change in shape or in binding energy positions of the Co $2 p_{1 / 2}$ at $796.3(2) \mathrm{eV}$ or $\mathrm{Co} 2 p_{3 / 2}$ at 780.4(2) eV for all temperatures, indicating more Co diffusing to the surface exhibiting a similar oxidation state through all annealing temperatures. Compared to reference 


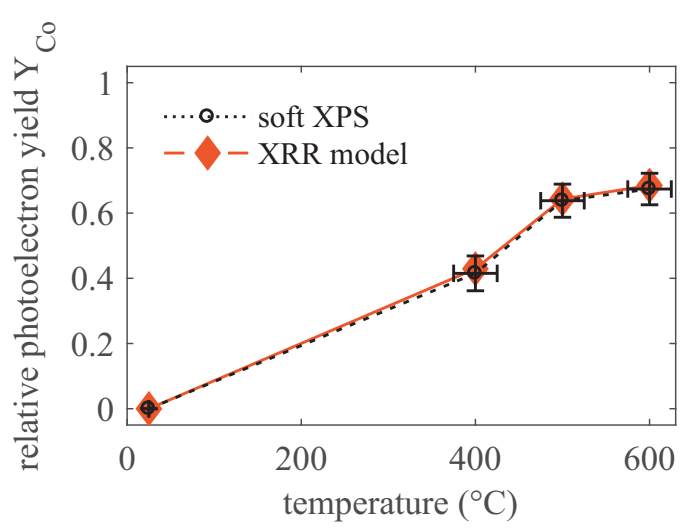

FIG. 4. Relative photoelectron yield $Y_{\text {Co }}$ determined by soft XPS analysis of $\mathrm{Fe} 2 p$ and $\mathrm{Co} 2 p$ spectra for sample A. The data coincide with the values determined theoretically based on the model of ferrite film and segregated $\mathrm{CoO}$ film (cf. Fig. 1) used to describe the XRR results.

spectra reported in the literature, the observed shape of Co $2 p$ spectra with characteristic shake-up satellites at 6.1(5) eV higher binding energies than the Co $2 p_{1 / 2}$ and Co $2 p_{3 / 2}$ photoelectron peaks can be attributed to $\mathrm{Co}^{2+}$ states as expected in $\mathrm{CoO}$ and $\mathrm{CoFe}_{2} \mathrm{O}_{4}$ [41-43].

Additionally, a quantitative analysis of the soft photoemission spectra was performed. The intensities $I_{\mathrm{Fe}}$ and $I_{\mathrm{Co}}$ from Fe $2 p$ and Co $2 p$ spectra have been numerically integrated after subtracting a Shirley background and the relative photoelectron yield

$$
Y_{\mathrm{Co}}=\frac{I_{\mathrm{Co}} / \sigma_{\mathrm{Co}}}{I_{\mathrm{Co}} / \sigma_{\mathrm{Co}}+I_{\mathrm{Fe}} / \sigma_{\mathrm{Fe}}}
$$

of Co has been calculated, using the differential photoionization cross sections from Trzhaskovskaya et al. [44]. The results for this calculation obtained from soft $\mathrm{x}$-ray photoemission data for the exemplary sample A are depicted in Fig. 4. From the layer models obtained by XRR analysis (thicknesses of top CoO film and Co ferrite film, Co content of ferrite film; see Sec. III A) we calculated the expected photoelectron yield $Y_{\mathrm{Co}}$, which is shown in Fig. 4 for comparison. One can see that the models describing the XRR results match perfectly with the yields obtained from soft XPS data. This observation corroborates the layer models we used to calculate the XRR data. Especially, due to the high surface sensitivity of soft XPS, the presence of a segregated $\mathrm{CoO}$ layer on top after all annealing steps is confirmed by this comparison.

For samples B and C similar agreements of layer model and soft $\mathrm{x}$-ray photoemission data are obtained (see Supplemental (a)

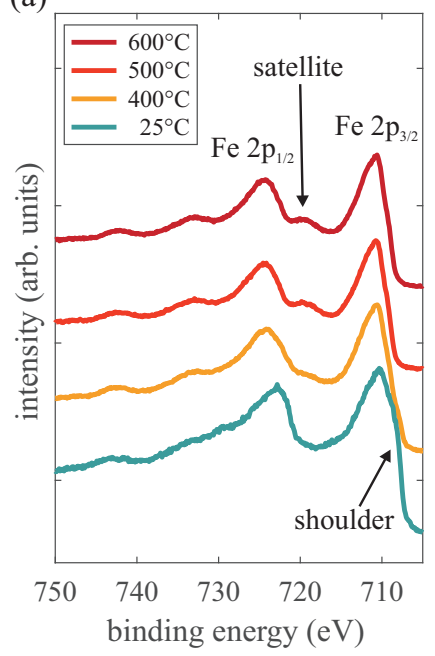

(b)

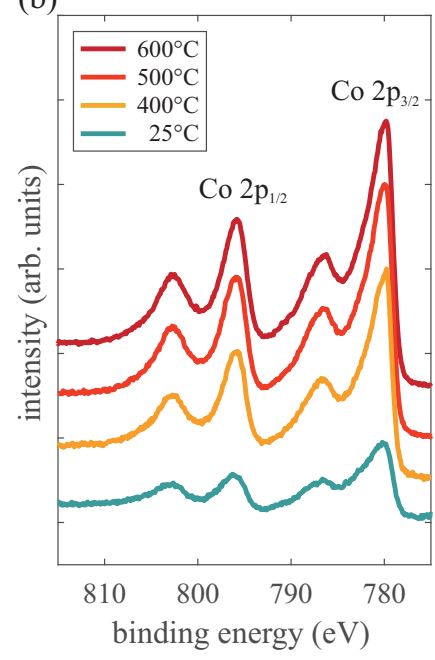

FIG. 5. HAXPES results (angular integrated spectra) of sample A of (a) Fe $2 p$ and (b) Co $2 p$ core-level spectra after annealing at different temperatures.

Material [38]). A comparison of the positions of Fe $2 p$ peaks for each sample after the last annealing step of $600{ }^{\circ} \mathrm{C}$ is listed in Table III. For increasing Co contents $x$ in the $\mathrm{Co}_{x} \mathrm{Fe}_{3-x} \mathrm{O}_{4}$ films the $\mathrm{Fe} 2 p_{1 / 2}$ and $\mathrm{Fe} 2 p_{3 / 2}$ positions in soft XPS data shift to higher binding energies implying a decreasing $\mathrm{Fe}^{2+}$ amount. The more Co is incorporated into the ferrite-like film, the higher is the $\mathrm{Fe}^{3+} / \mathrm{Fe}^{2+}$ ratio within the film, which is reasonable considering an increasing replacement of $\mathrm{Fe}^{2+}$ by $\mathrm{Co}^{2+}$ ions accompanied with oxidation of $\mathrm{Fe}^{2+}$ to $\mathrm{Fe}^{3+}$ with higher Co content.

\section{HAXPES}

In contrast to soft XPS, HAXPES gives information about the stoichiometry and chemical properties not only at the surface, but also in bulk due to the high kinetic energy of excited photoelectrons, which provide a higher information depth (cf. Table I). In addition, by using a two-dimensional detector in angular mode, we collected photoelectrons for different photoemission angles between $0^{\circ}$ and $60^{\circ}$ with respect to the surface normal in order to get depth-dependent information about valence states and stoichiometries in our films after each annealing step.

Figure 5 shows the Fe $2 p$ and Co $2 p$ core level spectra obtained by HAXPES summed up over the whole acceptance angle of the detector for each annealing step of sample A. The Fe $2 p$ spectrum for the as-prepared sample after transport

TABLE III. Co content $x$ in the $\mathrm{Co}_{x} \mathrm{Fe}_{3-x} \mathrm{O}_{4}$ film and $\mathrm{Fe} 2 p_{1 / 2}$ and $\mathrm{Fe} 2 p_{3 / 2}$ positions in soft x-ray photoemission and HAXPES data after the last annealing step of $600^{\circ} \mathrm{C}$ for samples $\mathrm{A}, \mathrm{B}$, and $\mathrm{C}$.

\begin{tabular}{|c|c|c|c|c|c|}
\hline & \multirow{2}{*}{$\begin{array}{c}\text { Co content } \\
x\end{array}$} & \multicolumn{2}{|c|}{ Soft XPS } & \multicolumn{2}{|c|}{ HAXPES } \\
\hline & & $\mathrm{Fe} 2 p_{1 / 2}(\mathrm{eV})$ & $\mathrm{Fe} 2 p_{3 / 2}(\mathrm{eV})$ & $\mathrm{Fe} 2 p_{1 / 2}(\mathrm{eV})$ & $\mathrm{Fe} 2 p_{3 / 2}(\mathrm{eV})$ \\
\hline Sample A & 0.98 & 724.4 & 710.8 & 724.3 & 710.8 \\
\hline Sample B & 0.76 & 724.3 & 710.7 & 724.1 & 710.6 \\
\hline Sample C & 0.37 & 723.9 & 710.4 & 723.6 & 710.4 \\
\hline
\end{tabular}




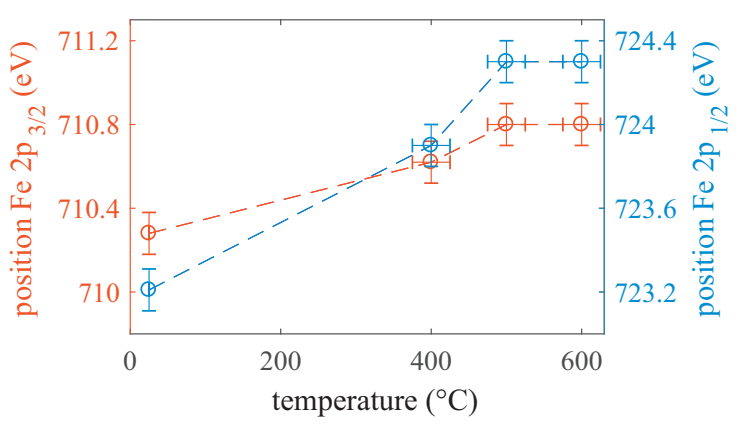

FIG. 6. Fe $2 p_{3 / 2}$ and $\mathrm{Fe} 2 p_{1 / 2}$ positions of sample A derived from HAXPES Fe $2 p$ core level spectra after annealing at different temperatures.

under ambient conditions to DLS/DESY shows no distinct satellite in between the $\mathrm{Fe} 2 p_{1 / 2}$ and $\mathrm{Fe} 2 p_{3 / 2}$ peaks. As mentioned before for our soft XPS studies, this implies a mixture of $\mathrm{Fe}^{2+}$ and $\mathrm{Fe}^{3+}$ valencies and confirms that the magnetite film is stable and did not undergo further oxidation or reduction during transport.

The Co $2 p$ spectrum before annealing exhibits a weak but significant signal due to damping of the excited photoelectrons in the overlying $14 \mathrm{~nm}$ thick $\mathrm{Fe}_{3} \mathrm{O}_{4}$ film. The higher binding energy satellites at $6.5(5) \mathrm{eV}$ above the Co $2 p_{1 / 2}$ and $\mathrm{Co} 2 p_{3 / 2}$ signals are characteristic for predominantly present $\mathrm{Co}^{2+}$ states, which indicates that the initial $\mathrm{CoO}$ film underneath the $\mathrm{Fe}_{3} \mathrm{O}_{4}$ layer is stable [41].

For the first annealing step of $400^{\circ} \mathrm{C}$ a weak satellite in the Fe $2 p$ spectra at 719.1(3) eV arises and becomes more distinguishable for further annealing at $500^{\circ} \mathrm{C}$ and $600^{\circ} \mathrm{C}$, which indicates a major amount of $\mathrm{Fe}^{3+}$ present in the ferrite film. In addition, the low binding energy shoulder of the Fe $2 p_{3 / 2}$ signal, resulting from $\mathrm{Fe}^{2+}$ valence states and clearly visible for the as-prepared sample [marked in Fig. 5(a)], significantly decreases and vanishes after annealing at $500{ }^{\circ} \mathrm{C}$ confirming a decline of $\mathrm{Fe}^{2+}$ states. Furthermore, the positions of the $\mathrm{Fe}$ $2 p_{1 / 2}$ and $\mathrm{Fe} 2 p_{3 / 2}$ signals shift to higher binding energies with higher annealing temperatures, as shown in Fig. 6, which also corresponds to $\mathrm{Fe}^{3+}$ excess [39]. Between $500^{\circ} \mathrm{C}$ and $600{ }^{\circ} \mathrm{C}$ there is not a significant change in the shape of the $\mathrm{Fe}$ $2 p$ spectra or in the position of Fe $2 p_{1 / 2}$ and Fe $2 p_{3 / 2}$ signals, revealing no further changes of $\mathrm{Fe}$ valence states and pointing to an equilibrium state of the interdiffusion process obtained after annealing at $500^{\circ} \mathrm{C}$.

From the first annealing step on, the intensity of the Co $2 p$ spectrum increases according to the interdiffusion process of Co into the magnetite film and segregation to the surface. The shape of the Co $2 p$ signal during annealing remains the same with shake-up satellites characteristic for $\mathrm{Co}^{2+}$ valence states $[41,43]$, which is in accordance with the formation of $\mathrm{CoO}$ as well as $\mathrm{CoFe}_{2} \mathrm{O}_{4}$, where in both cases only $\mathrm{Co}^{2+}$ is present.

For samples B and $\mathrm{C}$ a similar but not as distinct behavior is observed in Fe $2 p$ and Co $2 p$ core-level spectra (see Supplemental Material [38]). For comparison, the positions of Fe $2 p_{1 / 2}$ and $\mathrm{Fe} 2 p_{3 / 2}$ photoelectron peaks obtained by HAXPES after the last annealing step are given for all three samples in Table III. Here, the same tendency of decreasing binding energy positions for lower Co content in the ferrite film as for soft XPS is observed. Hence, the $\mathrm{Fe}^{3+}$ content rises not

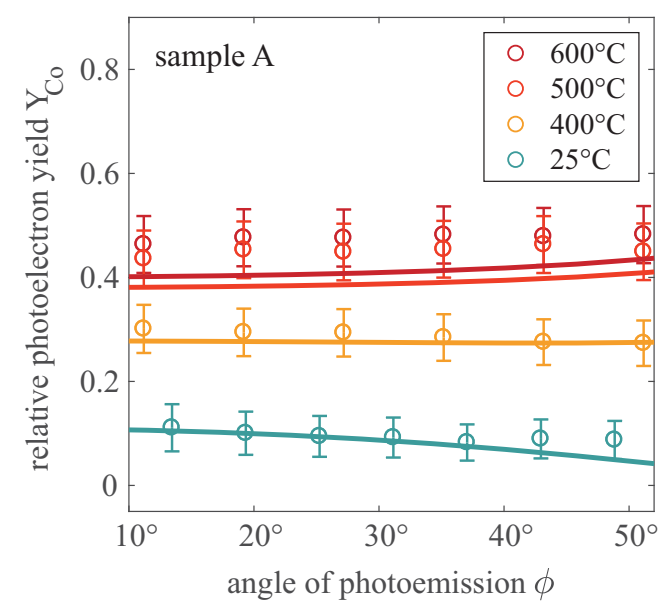

FIG. 7. Relative photoelectron yields $Y_{\mathrm{Co}}$ for sample A at different detection angles determined after the different annealing steps. The lines represent calculated values using the models determined by XRR analysis.

only in the near-surface region, but also throughout the whole ferrite-like film, as the Co content increases.

A quantitative analysis of HAXPES data was performed using Eq. (3) with the differential photoionization cross sections from Trzhaskovskaya et al. [44] for the used excitation energies of $h v=5930 \mathrm{eV}$ (DLS) and $h v=5948 \mathrm{eV}$ (DESY) and considering nondipole parameters of the photoelectron angular distribution $[44,45]$. The resulting photoelectron yields $Y_{\text {Co }}$ for different detection angles $\phi$ with respect to the surface normal are shown in Fig. 7 for the exemplary sample A. In addition, calculated photoelectron yields for the different annealing steps using the layer models determined by XRR analysis (cf. Sec. III A) are also shown as continuous lines for comparison. Note that lower emission angles contain more bulk information whereas for higher emission angles the near-surface region is taken more into account.

For the as-prepared sample the yields slightly decrease for higher emission angles, which is expected and well described by the $\mathrm{Fe}_{3} \mathrm{O}_{4} / \mathrm{CoO}$ bilayer stack existing before annealing. After annealing the sample at $400{ }^{\circ} \mathrm{C}$ the relative photoelectron yield $Y_{\mathrm{Co}}$ increases, which points to interdiffusion of $\mathrm{CoO}$ and $\mathrm{Fe}_{3} \mathrm{O}_{4}$. The data are also well described by the curve derived from the respective $\mathrm{CoO} / \mathrm{Fe}_{3} \mathrm{O}_{4} / \mathrm{CoO} \mathrm{XRR}$ model. Furthermore, there is no significant angular dependency observed implying homogeneously distributed Co ions in the ferrite film. By further annealing the photoelectron yield increases again, but does not undergo significant changes comparing the $500{ }^{\circ} \mathrm{C}$ and $600{ }^{\circ} \mathrm{C}$ annealing steps. A slight increase for higher photoemission angles results from the segregated $\mathrm{CoO}$ layer on top. Both respective layer models give similar expected curves, but also slightly underestimate the measured data.

A similar behavior is observed for sample B, where the interdiffusion process is also completed after annealing at $500{ }^{\circ} \mathrm{C}$ (see Supplemental Material [38]). Instead, for sample $\mathrm{C}$ exhibiting the lowest $\mathrm{Co}$ amount there is no change visible anymore after the first annealing step of $400^{\circ} \mathrm{C}$. The photoelectron yield remains the same over all photoemission 


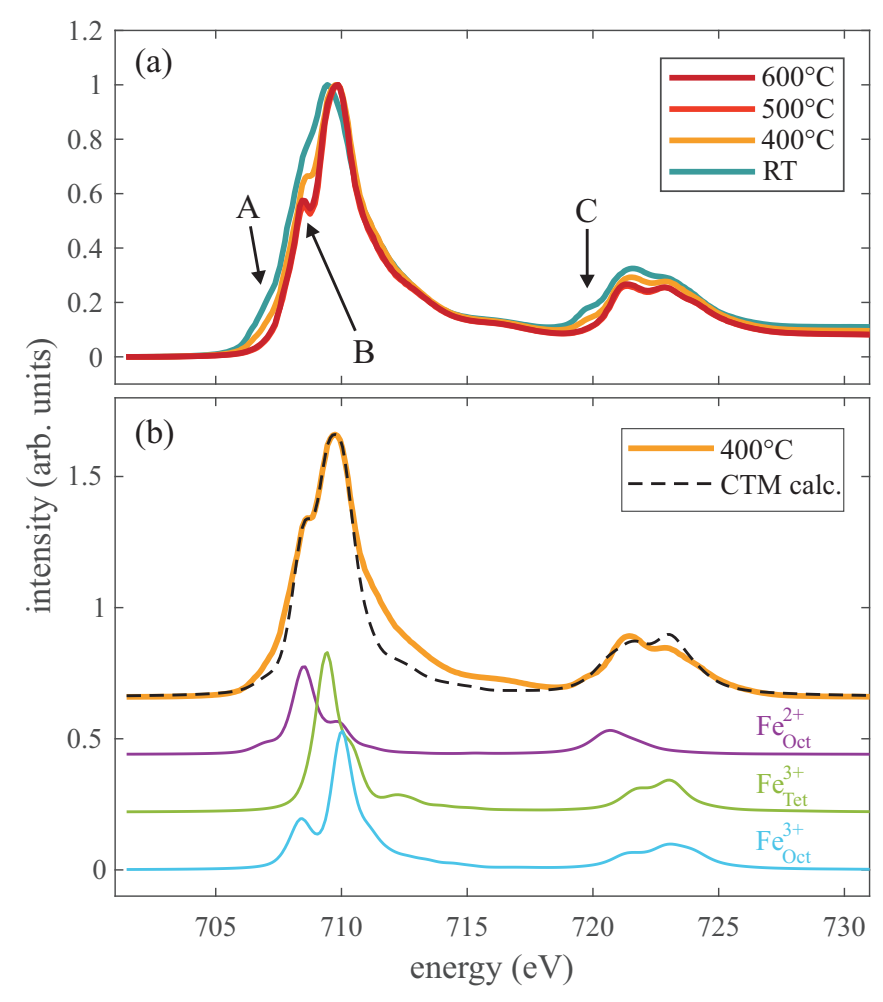

FIG. 8. (a) Experimental Fe $L_{2,3}$-edge x-ray absorption spectra for sample A after each annealing step. (b) Exemplary comparison between experimental $\mathrm{Fe} L_{2,3}$-edge spectrum after annealing at $400{ }^{\circ} \mathrm{C}$ and corresponding CTM calculation. The total CTM spectrum is a superposition of the individual octahedrally coordinated $\mathrm{Fe}^{2+}$ and tetra- and octahedrally coordinated $\mathrm{Fe}^{3+}$ spectra shown below.

angles and applied temperatures, indicating a completely and homogeneously intermixed $\mathrm{Co}_{0.37} \mathrm{Fe}_{2.63} \mathrm{O}_{4}$ film.

\section{XAS}

As a further complementary investigation to the photoemission measurements presented above, soft x-ray absorption spectroscopy has been performed. For sample A, the iron and cobalt $L_{2,3}$-edge absorption spectra after each annealing step are depicted in Figs. 8(a) and 9(a), respectively. The spectra were scaled to their maximum at the $L_{3}$ edge at around $\sim 709.6(2) \mathrm{eV}$ and $\sim 778.0 \mathrm{eV}$ for the Fe and Co $L_{3}$ edge, respectively, in order to compare different features and spectral shapes without considering absolute intensity values.

The Fe $L_{2,3}$-edge spectrum of the as-prepared sample, recorded directly after transport to DLS, consists of two pre-edge features at the $L_{3}$ and $L_{2}$ edges marked by "A" and " $C$ " in Fig. 8(a), respectively. These features in addition to broad $L_{3}$ and $L_{2}$ edges are characteristic for a mixture of $\mathrm{Fe}^{2+}$ and $\mathrm{Fe}^{3+}$ valence states and confirm the soft XPS results of a stable $\mathrm{Fe}_{3} \mathrm{O}_{4}$ phase at the surface $[29,46]$. After annealing at $400^{\circ} \mathrm{C}$ features " $\mathrm{A}$ " and " $\mathrm{C}$ " decline compared to the as-prepared sample. In addition, a small energy shift of the maximum of the $L_{3}$ edge from $709.4 \mathrm{eV}$ to $709.8 \mathrm{eV}$ is observed. Furthermore, the width of the $L_{3}$ edge decreases accompanied by an increasingly distinct feature " $\mathrm{B}$ " at the

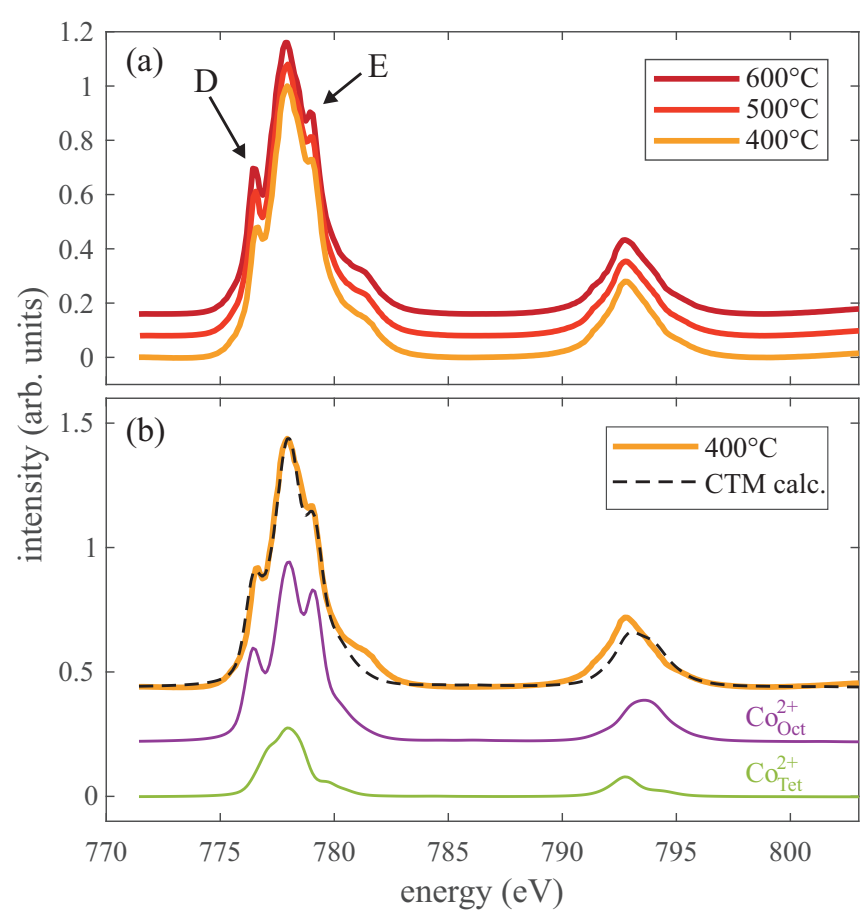

FIG. 9. (a) Experimental Co $L_{2,3}$-edge $x$-ray absorption spectra for sample A after each annealing step. (b) Exemplary comparison between experimental Co $L_{2,3}$-edge spectrum at $400^{\circ} \mathrm{C}$ and corresponding CTM calculation. The total CTM spectrum is a superposition of the individual octahedrally and tetrahedrally coordinated $\mathrm{Co}^{2+}$ spectra shown below.

low excitation energy side of the $L_{3}$ edge. This behavior is even more pronounced for the annealing step of $500{ }^{\circ} \mathrm{C}$, while further increasing the temperature to $600{ }^{\circ} \mathrm{C}$ does not change the spectral shape significantly. This leads to the assumption that for the last two annealing steps of $500^{\circ} \mathrm{C}$ and $600^{\circ} \mathrm{C}$, an equilibrium state of the $\mathrm{Fe}^{2+} / \mathrm{Fe}^{3+}$ cation distribution is reached. Shape and intensity ratios of both last spectra are comparable to $\mathrm{Fe} L_{2,3}$-edge spectra in the literature of $\mathrm{Fe}_{2} \mathrm{O}_{3}$ and $\mathrm{CoFe}_{2} \mathrm{O}_{4}$, where only $\mathrm{Fe}^{3+}$ cations are present [28,34,46-49].

In contrast to the Fe $L_{2,3}$-edge spectra, the Co $L_{2,3}$-edge spectra do not undergo significant changes upon annealing, as shown in Fig. 9(a). Hence, these spectra were additionally shifted on the intensity axis for clarity. For the as-prepared sample there was no signal observed in this energy range, since the absorption of the buried $\mathrm{CoO}$ layer cannot be measured in the surface-sensitive TEY mode. For all annealing steps from $400{ }^{\circ} \mathrm{C}$ to $600{ }^{\circ} \mathrm{C}$ the spectral shape closely resembles absorption spectra of $\mathrm{CoO}$ and $\mathrm{CoFe}_{2} \mathrm{O}_{4}$ reported in the literature, wherein Co solely exists in the $\mathrm{Co}^{2+}$ valence state [33,50,51].

For samples B and C the spectral shapes and their evolution during annealing are similar to the XAS spectra of sample A (see Supplemental Material [38]). Only the features "A" to "E" are not as pronounced as for sample A. In the following, a quantitative analysis is applied only for sample $\mathrm{A}$, which solely forms stoichiometric $\mathrm{CoFe}_{2} \mathrm{O}_{4}$ after PDA treatment.

The individual spectra for each cation and lattice site as well as total CTM spectra for the Fe and Co $L_{2,3}$ edges 
are exemplarily shown in Figs. 8(b) and 9(b), respectively, along with corresponding experimental XAS data of sample A after the annealing step of $400^{\circ} \mathrm{C}$. For the $\mathrm{Fe} L_{2,3}$ edges, $\mathrm{Fe}^{2+}$ and $\mathrm{Fe}^{3+}$ cations on octahedral $\left(\mathrm{Fe}_{\mathrm{Oct}}^{2+}, \mathrm{Fe}_{\mathrm{Oct}}^{3+}\right)$ and $\mathrm{Fe}^{3+}$ cations on tetrahedral sites $\left(\mathrm{Fe}_{\text {Tet }}^{3+}\right)$ have been considered in CTM calculations to reproduce the experimental spectra. The crystal fields $10 D q$ for $\mathrm{Fe}_{\text {Oct }}^{2+}$ and $\mathrm{Fe}_{\text {Oct }}^{3+}$ were set to $1.15 \mathrm{eV}$ and $1.2 \mathrm{eV}$, respectively, whereas for $\mathrm{Fe}_{\text {Tet }}^{3+}$ cations $-0.5 \mathrm{eV}$ was used, agreeing with values used for $\mathrm{Fe}_{3} \mathrm{O}_{4}$ in previous studies [30,32]. Regarding the Fe $L_{2,3}$ edge in Fig. 8(b), the absorption spectrum of $\mathrm{Fe}_{\text {Oct }}^{2+}$ mainly contributes to the lowenergy sides of the $L_{3}$ and $L_{2}$ edges, corresponding to features "A" and "C" in the experimental spectra. In contrast, mostly $\mathrm{Fe}_{\text {Oct }}^{3+}$ and $\mathrm{Fe}_{\text {Tet }}^{3+}$ spectra contribute to the most intense line of the $L_{3}$ edge at $\sim 709.8 \mathrm{eV}$, while feature "B" at $\sim 708.5 \mathrm{eV}$ only becomes distinguishable from the main $L_{3}$ absorption line if the ratio of $\mathrm{Fe}_{\mathrm{Oct}}^{3+}$ to $\mathrm{Fe}_{\mathrm{Oct}}^{2+}$ increases (see Supplemental Material [38]). Therefore, the decreasing $\mathrm{Fe}^{2+} / \mathrm{Fe}^{3+}$ ratio with higher annealing temperatures founded by a decrease of features " $\mathrm{A}$ " and "C" and an increasingly distinct feature "B" is manifested by CTM calculations.

For the description of the experimental $\mathrm{Co} L_{2,3}$ edges, $\mathrm{Co}^{2+}$ cations in octahedral $\left(\mathrm{Co}_{\mathrm{Oct}}^{2+}\right)$ and tetrahedral coordination $\left(\mathrm{Co}_{\mathrm{Tet}}^{2+}\right)$ had to be considered [cf. Fig. 9(b)]. Here, crystal fields of $10 D q=1.0 \mathrm{eV}$ for $\mathrm{Co}_{\text {Oct }}^{2+}$ and $10 D q=-0.6 \mathrm{eV}$ for $\mathrm{Co}_{\text {Tet }}^{2+}$ were chosen. By comparing the individual $\mathrm{Co}^{2+} \mathrm{CTM}$ spectra with the experimental Co $L_{2,3}$ edges, it becomes evident that the predominant low and high energy shoulders of the Co $L_{3}$ edge (features "D" and "E") originate from octahedrally coordinated $\mathrm{Co}^{2+}$ cations. Nevertheless, the absorption of $\mathrm{Co}_{\text {Tet }}^{2+}$, which mostly contributes to the main absorption line of the Co $L_{3}$ edge at $\sim 778.0 \mathrm{eV}$ and the low-energy side of the Co $L_{2}$ edge, has to be added in order to appropriately reproduce the experimental spectra. Although $\mathrm{Co}^{2+}$ should only occupy octahedral lattice sites in a perfect inverse spinel, this observation is in agreement with most studies on $\mathrm{CoFe}_{2} \mathrm{O}_{4}$ thin films and nanoparticles in the literature, which report an amount of tetrahedrally coordinated $\mathrm{Co}^{2+}$ cations of up to $30 \%$ in the ferrite $[34,48,49,52]$.

For a quantitative determination of the cation occupancy in the ferrite layer, it has to be considered that the Co XAS signal is also caused by both the cobalt ferrite film and the segregated $\mathrm{CoO}$ layer at the surface. Here, we assume that the tetrahedral $\mathrm{Co}^{2+}$ cations are not present in the $\mathrm{CoO}$ layer and solely originate from the ferrite film, while the octahedral $\mathrm{Co}^{2+}$ XAS signal is a superposition of the absorption in the cobalt ferrite and the segregated $\mathrm{CoO}$ film on top. For a simple estimation of the octahedral and tetrahedral $\mathrm{Co}^{2+}$ occupancy in the CFO film, we consider an exponential attenuation of the signal stemming from the ferrite layer by the $0.8 \mathrm{~nm}$ thick $\mathrm{CoO}$ layer on top. The resulting occupancies of $\mathrm{Fe}^{2+}, \mathrm{Fe}^{3+}$, and $\mathrm{Co}^{2+}$ cations on the different lattice sites of the ferrite film per formula unit are depicted in Fig. 10.

The as-prepared sample with the $\mathrm{Fe}_{3} \mathrm{O}_{4} / \mathrm{CoO}$ bilayer exhibits $\mathrm{Fe}_{\mathrm{Oct}}^{2+}, \mathrm{Fe}_{\mathrm{Oct}}^{3+}$, and $\mathrm{Fe}_{\mathrm{Tet}}^{3+}$ amounts, which slightly deviate from each other, but considering measurement errors still attain the ideal value for magnetite of one per f.u. of the cations mentioned above. During PDA treatment the amounts of $\mathrm{Fe}_{\text {Oct }}^{2+}$ and $\mathrm{Fe}_{\mathrm{Tet}}^{3+}$ decrease, while $\mathrm{Fe}_{\mathrm{Oct}}^{3+}$ is approximately constant. The

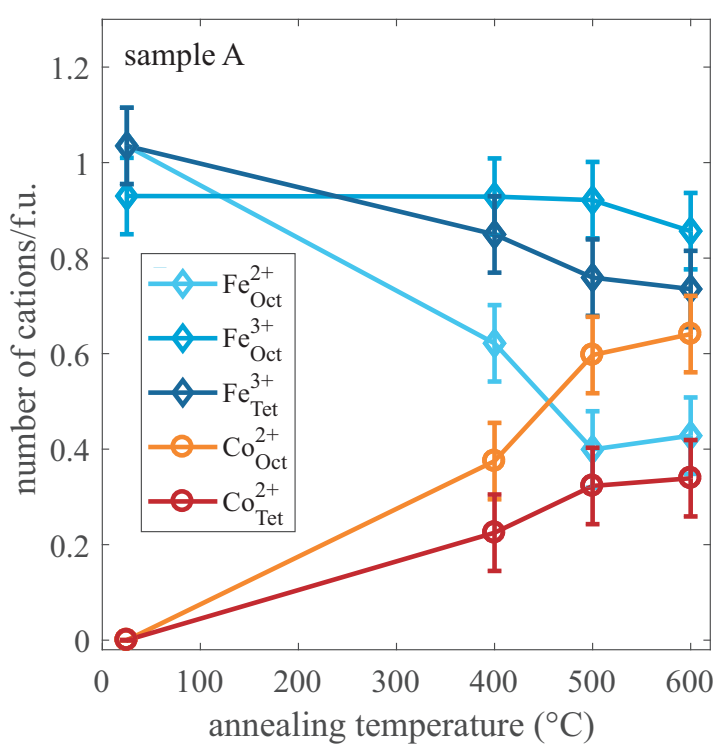

FIG. 10. Occupancies of the different cations in the ferrite film per formula unit of sample A for different annealing temperatures estimated by CTM calculations compared to experimental XAS spectra.

decreasing $\mathrm{Fe}_{\mathrm{Oct}}^{2+}$ and $\mathrm{Fe}_{\text {Tet }}^{3+}$ proportions are accompanied by an increase of $\mathrm{Co}_{\mathrm{Oct}}^{2+}$ and $\mathrm{Co}_{\mathrm{Tet}}^{2+}$, indicating a direct substitution of $\mathrm{Fe}_{\mathrm{Oct}}^{2+}$ by $\mathrm{Co}_{\mathrm{Oct}}^{2+}$ and $\mathrm{Fe}_{\text {Tet }}^{3+}$ by $\mathrm{Co}_{\text {Tet }}^{2+}$, which is also reported in the literature [48]. Only for the last annealing step the $\mathrm{Fe}_{\text {Oct }}^{2+}$ amount stays constant while the $\mathrm{Co}_{\text {Oct }}^{2+}$ amount is still increasing. For this temperature step the $\mathrm{Co}_{\text {Oct }}^{2+}$ cations seem to begin substituting $\mathrm{Fe}_{\mathrm{Oct}}^{3+}$ cations, as these are slightly decreasing for this annealing step. After the last PDA step of $600{ }^{\circ} \mathrm{C}$, $\mathrm{Co}_{\text {Oct }}^{2+}$ and $\mathrm{Co}_{\text {Tet }}^{2+}$ reach values of 0.64 and 0.34 cations/f.u., respectively. The degree of inversion $\gamma$, which expresses the amount of divalent cations located on octahedral sites, attains a value of $\gamma=0.76$ for the stoichiometric $\mathrm{CoFe}_{2} \mathrm{O}_{4}$ film in sample A, agreeing with previous studies on $\mathrm{CoFe}_{2} \mathrm{O}_{4}$ thin films, nanocrystals, and nanoparticles [52-54]. After PDA treatment the $\mathrm{CoFe}_{2} \mathrm{O}_{4}$ film of sample A still exhibits an amount of 0.43 cations/f.u. of $\mathrm{Fe}_{\mathrm{Oct}}^{2+}$, although a $\mathrm{Co}: \mathrm{Fe}$ ratio of $1: 2$ is present. This residual $\mathrm{Fe}_{\mathrm{Oct}}^{2+}$ amount reduces the total cationic charge, which results-in order to reach charge neutrality-in a reduction of the amount of oxygen in the ferrite unit cell. This can be realized by the assumption of present oxygen vacancies. Hence, the chemical composition of the final ferrite film can be described by a small reduction $\delta$ of oxygen atoms in the formula unit leading to a $\mathrm{CoFe}_{2} \mathrm{O}_{4-\delta}$ stoichiometry.

\section{E. SQUID}

Magnetic measurements of the ferrite films were conducted for sample A before and after PDA treatment by superconducting quantum interference device magnetometry. To minimize thermal fluctuations the sample was cooled down to $5 \mathrm{~K}$ in zero field. The total magnetization $M$ was recorded dependent on the applied magnetic field $\mu_{0} H$, which was tuned from $+7 \mathrm{~T}$ to $-7 \mathrm{~T}$ and back again in in-plane geometry parallel to the [100] direction of substrate and film. The 


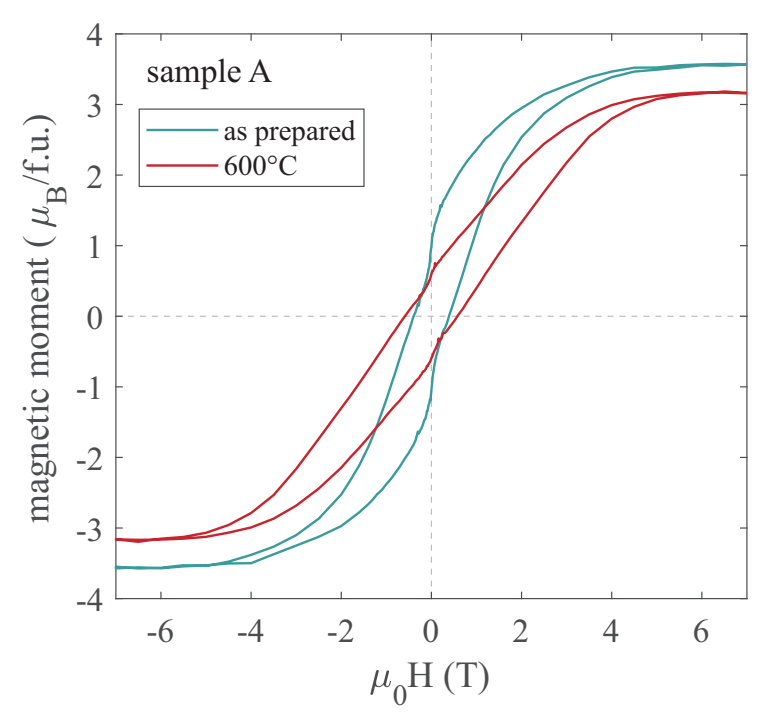

FIG. 11. $M$ vs $H$ curves for sample A before PDA treatment (as prepared) and after the last annealing step of $600^{\circ} \mathrm{C}$ measured by SQUID magnetometry at $5 \mathrm{~K}$ after zero-field cooling.

resulting $M$ vs $H$ curves for the as-prepared sample A and after the last annealing step of $600^{\circ} \mathrm{C}$ are shown in Fig. 11 . In order to obtain the magnetic response only from the ferrite layer a linear background, which stems from diamagnetic contributions from substrate and sample holder, was subtracted from the data. The magnetization was converted into magnetic moments in units of $\mu_{B} /$ f.u.

The $M$ vs $H$ measurements before and after PDA treatment of sample A show hysteresis loops characteristic for ferro/ferrimagnetic (FM) material. Only at low fields a stronger shrinkage in the magnetization is noticed. This behavior is explained in the literature by strain effects [55], easy-plane anisotropy configuration and dipolar interactions [56], interparticle interactions in nanophase materials [57], formation of pyramidal huts on continuous films [58], multidomain phases [59], or coexisting antiferromagnetic (AFM) and FM ordered phases $[60,61]$. The latter could be one explanation for the behavior observed in the $M$ vs $H$ curves of sample A before and after PDA treatment. Here, the $\mathrm{CoO}$ film as an antiferromagnet at the measurement temperature of $5 \mathrm{~K}$ couples to the ferrimagnetic ferrite layer and could be responsible for the "wasp-waist" shape of the hysteresis curves. Both curves show magnetic saturation at fields above 6 T. Magnetic saturation $M_{s}$, remanent magnetization $M_{r}$ at $\mu_{0} H=0 \mathrm{~T}$ (in relation to $M_{s}$ ), and coercive field $H_{c}$ for $M=0 \mu_{B} /$ f.u. for sample A as grown and after the final PDA step are listed in Table IV.

For the $\mathrm{CoFe}_{2} \mathrm{O}_{4}$ film (after annealing at $600{ }^{\circ} \mathrm{C}$ ) an increased coercive field as well as a lower $M_{r} / M_{s}$ ratio compared to the as-prepared $\mathrm{Fe}_{3} \mathrm{O}_{4}$ layer are observed, both of which can be attributed to a higher density of defects in the interdiffused film. The measured magnetic saturation values deviate from calculated values for $\mathrm{Fe}_{3} \mathrm{O}_{4}\left(3.72-4.00 \mu_{B}\right.$ /f.u. [62-65]) and $\mathrm{CoFe}_{2} \mathrm{O}_{4}\left(2.73-3.00 \mu_{B} /\right.$ f.u. $\left.[62,63,66,67]\right)$. As the cation occupancy of the different lattice sites in the (inverse) spinel structure is a determining factor for magnetic ordering, these deviations may be attributed to partial inversion
TABLE IV. Coercive field $H_{c}$, remanence-to-saturation ratio $M_{r} / M_{s}$, and magnetic saturation $M_{s}$ obtained from hysteresis loops of the as-prepared $\mathrm{Fe}_{3} \mathrm{O}_{4}$ and the interdiffused $\mathrm{CoFe}_{2} \mathrm{O}_{4}$ film of sample A. The calculated saturation values $M_{s}(\mathrm{XAS})$ obtained from site occupancies, which were determined by XAS analysis, are listed for comparison.

\begin{tabular}{lcccc}
\hline \hline & $H_{c}(\mathrm{~T})$ & $M_{r} / M_{s}$ & $M_{s}\left(\mu_{B} /\right.$ f.u. $)$ & $M_{s}$ (XAS) $\left(\mu_{B} /\right.$ f.u. $)$ \\
\hline As prepared & 0.39 & 0.29 & $3.56 \pm 0.1$ & $3.62 \pm 0.2$ \\
$600{ }^{\circ} \mathrm{C}$ & 0.58 & 0.19 & $3.17 \pm 0.1$ & $3.22 \pm 0.2$ \\
\hline \hline
\end{tabular}

in the interdiffused $\mathrm{CoFe}_{2} \mathrm{O}_{4}$ film. To check this assumption we calculate the expected magnetic moments from the determined site occupancies resulting from XAS analysis. Here, we consider only ferromagnetic double-exchange between octahedrally coordinated cations as well as antiferromagnetic superexchange interaction between tetra- and octahedral sites. Furthermore, for this estimation only spin magnetic moments $m_{s}$ of the respective cations are considered and the mostly weak orbital contribution to the total magnetic moment of ferrites is neglected. With $m_{s}\left(\mathrm{Fe}^{2+}\right)=4 \mu_{B}, m_{s}\left(\mathrm{Fe}^{3+}\right)=$ $5 \mu_{B}, m_{s}\left(\mathrm{Co}^{2+}\right)=3 \mu_{B}$, and the cationic distribution in the ferrite thin film (cf. Fig. 10), we calculated magnetic saturation values $M_{s}(\mathrm{XAS})$, which are also listed in Table IV for comparison. Taking account of the measurement errors the calculated saturation moments are in excellent agreement with the measured $M_{s}$ values, which thereby reinforces the determined cationic distribution in the ferrite film by XAS analysis before and after PDA treatment. Only a very slight tendency to higher values in the magnetic saturation moments calculated from XAS results compared to the measured $M_{s}$ values is noticed.

\section{DISCUSSION}

From XRR measurements respective film models have been derived for different temperatures during the interdiffusion process in order to reproduce the data properly. For samples A and B with initially thick $\mathrm{CoO}$ films it has been necessary to include a thin segregated $\mathrm{CoO}$ film on top for annealing steps above $400{ }^{\circ} \mathrm{C}$. The determined layer models are confirmed by quantitative soft XPS analysis, which especially reinforces the presence of a segregated $\mathrm{CoO}$ layer at the top.

Sample A exhibits a slightly overstoichiometric (regarding the Co content) $\mathrm{Co}: \mathrm{Fe}$ ratio deduced from the initial $\mathrm{CoO}$ and $\mathrm{Fe}_{3} \mathrm{O}_{4}$ film thicknesses. Assuming a complete mixing of both films a ferrite film with a Co content of $x=1.06$ would be expected. As observed, this sample solely forms a ferrite layer with stoichiometric Co content $\left(x_{A}=1\right)$. The provided Co excess is used to form a thin $\mathrm{CoO}$ layer on top.

In contrast, the initial films of sample $\mathrm{B}$ and $\mathrm{C}$ exhibit understoichiometric $\mathrm{Co}: \mathrm{Fe}$ ratios. Even if both layers in sample B interdiffused completely, the Co content of $x_{B}=0.89$ would still be insufficient to form stoichiometric $\mathrm{CoFe}_{2} \mathrm{O}_{4}$. Instead, this sample exhibits a ferrite film with even less Co content of $x_{B}=0.76$ and a $\mathrm{CoO}$ layer on top after the last annealing step. This observation allows us to conclude that the segregation and formation of $\mathrm{CoO}$ above the ferrite layer already takes place before the stoichiometric $\mathrm{Co}: \mathrm{Fe}$ ratio of 
1:2 is reached in the ferrite film. This preferential formation of $\mathrm{CoO}$ points to a lower surface energy of $\mathrm{CoO}$ in contrast to $\mathrm{CoFe}_{2} \mathrm{O}_{4}$. A reliable determination of the surface energy of cobalt ferrite is still lacking in the literature. In contrast, the surface energy of $0.8 \mathrm{~J} / \mathrm{m}^{2}$ for $\mathrm{CoO}$ [68] is similar to the value of $0.863 \mathrm{~J} / \mathrm{m}^{2}$ found for $\mathrm{NiO}$ [69]. Thus, we also assume a value for $\mathrm{CoFe}_{2} \mathrm{O}_{4}$ similar to what has been reported for $\mathrm{NiFe}_{2} \mathrm{O}_{4}$ with a surface energy of $1.235 \mathrm{~J} / \mathrm{m}^{2}$ [69]. This value, and therefore an assumed similar surface energy for $\mathrm{CoFe}_{2} \mathrm{O}_{4}$, is significantly higher than the value for $\mathrm{CoO}$, which could explain the formation of the segregated $\mathrm{CoO}$ layer as has also been reported for the formation of nickel ferrite due to interdiffusion of $\mathrm{Fe}_{3} \mathrm{O}_{4} / \mathrm{NiO}$ bilayers [18]. In contrast, there is no formation of a $\mathrm{CoO}$ layer on top for sample $\mathrm{C}$ due to the low Co amount compared to the amount of Fe cations. Here, both films intermix completely building a ferrite-like film with a low Co amount of $x_{C}=0.37$. The hindered CoO segregation in this sample could also be due to the presence of the thickest initial $\mathrm{Fe}_{3} \mathrm{O}_{4}$ film compared to samples $\mathrm{A}$ and $\mathrm{B}$. As the evolution of the film stack of sample $\mathrm{C}$ still shows a small change between the last two annealing steps, the interdiffusion process does not necessarily have to be completed after PDA treatment as for samples A and B. Consequently, it cannot be excluded that this sample could have also formed a $\mathrm{CoO}$ layer on top if further thermal treatment had been applied or if the annealing time for each annealing step had been increased.

Both soft $x$-ray photoemission and HAXPES show a rise in intensity of Co $2 p$ core-level spectra during PDA treatment due to interdiffusion of $\mathrm{CoO}$ and $\mathrm{Fe}_{3} \mathrm{O}_{4}$, increasing the $\mathrm{Co} / \mathrm{Fe}$ ratio in near-surface regions. In addition, XPS, XAS, and HAXPES all reveal an increase of the $\mathrm{Fe}^{3+} / \mathrm{Fe}^{2+}$ ratio up to the $500{ }^{\circ} \mathrm{C}$ annealing step at the surface and in bulk. In contrast, the $\mathrm{Co}^{2+}$ valence state is stable throughout all annealing steps excluding other Co oxidation states in the whole film stack, which is expected for $\mathrm{CoO}$ and $\mathrm{Co}_{x} \mathrm{Fe}_{3-x} \mathrm{O}_{4}$ $(x \leqslant 1)$ as only $\mathrm{Co}^{2+}$ is present in both systems. These observations made in soft XPS, HAXPES, and XAS data for the different annealing steps of PDA treatment can be explained by a major replacement of octahedrally coordinated $\mathrm{Fe}^{2+}$ by $\mathrm{Co}^{2+}$ cations during interdiffusion. Therefore, if the correct Co:Fe ratio of $1: 2(x=1)$ is provided and all $\mathrm{Fe}_{\text {Oct }}^{2+}$ cations are replaced by $\mathrm{Co}_{\text {Oct }}^{2+}$, this would lead to the formation of stoichiometric and completely inverse cobalt ferrite. Here we observed that a higher Co:Fe ratio of 1.09:2 (sample A) has to be provided to form a stoichiometric $\mathrm{CoFe}_{2} \mathrm{O}_{4}$ film underneath the segregated $\mathrm{CoO}$ film. XAS analysis reveals that this CFO film still exhibits octahedrally coordinated $\mathrm{Fe}^{2+}$ cations, while $\mathrm{Co}^{2+}$ cations are localized on both octahedral and tetrahedral sites resulting in a partial inversion, which is in agreement with former studies on $\mathrm{CoFe}_{2} \mathrm{O}_{4}$ thin films [48,52]. Due to residual $\mathrm{Fe}_{\mathrm{Oct}}^{2+}$ in the $\mathrm{CFO}$ film after PDA treatment it is assumed that oxygen vacancies are present to preserve charge neutrality leading up to a $\mathrm{CoFe}_{2} \mathrm{O}_{4-\delta}$ film stoichiometry.

Between the annealing steps of $500^{\circ} \mathrm{C}$ and $600^{\circ} \mathrm{C}$ for samples $\mathrm{A}$ and $\mathrm{B}$ there is no major change visible in the respective Fe $2 p$, Co $2 p$ core-level spectra. Furthermore, there is no difference in the related film stacks for this temperature range, which leads to the assumption that an equilibrium state is reached. Only XAS analysis reveals that for this last annealing step a small amount of $\mathrm{Co}^{2+}$ starts to substitute octahedral $\mathrm{Fe}^{3+}$.

Regarding the angular-dependent HAXPES measurements, the photoelectron yields $Y_{\mathrm{Co}}$ are well described by the film models up to $400^{\circ} \mathrm{C}$ annealing temperature. For $500^{\circ} \mathrm{C}$ and $600^{\circ} \mathrm{C}$ the proposed models only very slightly underestimate the measured HAXPES data. This deviation can be explained by inhomogeneous cation distributions in the ferrite film. For all simulations made above, films with homogeneously distributed $\mathrm{Co}$ and $\mathrm{Fe}$ cations have been assumed; concentration gradients within the films have not been considered. For instance, assuming higher Co concentrations in deeper layers could explain the higher determined $Y_{\text {Co }}$ data in HAXPES and would not influence the measured photoelectron yield in soft $\mathrm{X}$-ray photoemission data due to its higher surface sensitivity.

In addition, as the formation of a thin $\mathrm{CoO}$ film on top of the layer stack appears to be favorable in contrast to forming stoichiometric cobalt ferrite, the emergence of inhomogeneously distributed $\mathrm{CoO}$ precipitates within the ferrite film could also cause the observed small deviation between model and measured HAXPES data. Such inhomogeneous Co distributions would also influence the layer models in XRR analysis, since the different electron densities of $\mathrm{CoFe}_{2} \mathrm{O}_{4}$ and $\mathrm{Fe}_{3} \mathrm{O}_{4}$ would cause different dispersions $\delta$, used as one fit parameter for each film in XRR analysis. The respective dispersions for the used $\mathrm{x}$-ray energy of $20 \mathrm{keV}$ are $2.59 \times 10^{-6}$ and $2.66 \times 10^{-6}$ for $\mathrm{Fe}_{3} \mathrm{O}_{4}$ and $\mathrm{CoFe}_{2} \mathrm{O}_{4}$, respectively [70]. Since these dispersions do not differ significantly from each other, a more detailed XRR analysis by layer segmentation of the ferrite film with independent dispersions for each layer would not be reasonable as also the degrees of freedom would blow out of proportion and an unambiguous layer model would not be able to be found. Further investigations like cross-sectional high-resolution transmission electron microscopy (HR-TEM) with complementary energy-dispersive $\mathrm{X}$-ray spectroscopy (EDX) studies could shed light on the lateral $\mathrm{Co}$ and $\mathrm{Fe}$ distributions in the ferrite films.

Comparing the measured saturation magnetizations with calculated $M_{s}$ values predicted from the determined cationic site distributions of sample A, one obtains an excellent agreement considering measurement errors. Nevertheless, the measured values for the as-prepared $\mathrm{Fe}_{3} \mathrm{O}_{4}$ and the interdiffused $\mathrm{CoFe}_{2} \mathrm{O}_{4}$ films are both slightly overestimated by the calculated prediction. One reason for this systematic deviation could be the neglected orbital magnetic moments in the calculations, which can significantly contribute to the total magnetic moment especially for $\mathrm{CoFe}_{2} \mathrm{O}_{4}$ thin films [71]. Another reason for reduced saturation magnetizations of ferrites can also be the presence of antiphase boundaries [72], which can be formed when crystal growth starts at different locations on substrates with a half as large lattice constant. In this case, islands that are structurally out of phase with each other upon merging can evolve, resulting in spin frustration at the boundaries. Nevertheless, the agreement between predicted and measured $M_{s}$ values serves as a confirmation of the determined cationic distributions and can solely be explained by the partial inversion of the interdiffused $\mathrm{CoFe}_{2} \mathrm{O}_{4}$ film. 


\section{SUMMARY AND CONCLUSIONS}

In this work we investigated the interdiffusion process of $\mathrm{Fe}_{3} \mathrm{O}_{4} / \mathrm{CoO}$ bilayers on $\mathrm{SrTiO}_{3}(001)$ in order to find an alternate pathway for the formation of $\mathrm{CoFe}_{2} \mathrm{O}_{4}$ thin films. Therefore, three samples with different initial $\mathrm{Fe}_{3} \mathrm{O}_{4} / \mathrm{CoO}$ film thickness ratios have been prepared by reactive molecular beam epitaxy. Postdeposition annealing experiments have been conducted at beamlines I07 and I09 at DLS and P09 at DESY to monitor the interdiffusion process by combining $\mathrm{x}$-ray reflectivity, soft XPS, XAS, and high-resolution angle-resolved hard $\mathrm{X}$-ray photoelectron spectroscopy to determine the film structure, stoichiometry, and chemical properties for different annealing temperatures during the interdiffusion process. SQUID magnetometry serves as a magnetic characterization before and after PDA treatment.

From XRR measurements layer models for each annealing step could be derived and are confirmed by soft X-ray photoemission and XAS data and HAXPES results. The interdiffusion process starts from $300{ }^{\circ} \mathrm{C}$ annealing temperature and is completed for temperatures above $500{ }^{\circ} \mathrm{C}$. During interdiffusion a $\mathrm{CoO}$ layer is formed on top of the film stack due to segregation through the ferrite film, even if the provided $\mathrm{Co}$ amount is not sufficient to form stoichiometric $\mathrm{CoFe}_{2} \mathrm{O}_{4}$. Consequently, in order to form a stoichiometric cobalt ferrite film by the proposed PDA treatment, one has to provide more Co than is necessary, allowing a certain amount of $\mathrm{CoO}$ forming a segregated $\mathrm{CoO}$ layer on top. This has been succesfully achieved for one sample with a stoichiometric
$\mathrm{CoFe}_{2} \mathrm{O}_{4}$ film underneath a $0.8 \mathrm{~nm}$ thin segregated $\mathrm{CoO}$ layer on top.

Angular-dependent HAXPES investigations of this final film stack only slightly deviate from the predicted layer model, which can be explained by potential concentration gradients or by $\mathrm{CoO}$ precipitates within the ferrite film. HAXPES, XAS, and soft XPS data reveal a partial replacement of $\mathrm{Fe}^{2+}$ by $\mathrm{Co}^{2+}$ cations accompanied with an oxidation of $\mathrm{Fe}^{2+}$ to $\mathrm{Fe}^{3+}$ in bulk and at the surface, respectively. The final stoichiometric ferrite film exhibits a major amount of $\mathrm{Fe}^{3+}$ and only $\mathrm{Co}^{2+}$ valence states as expected for cobalt ferrite. $\mathrm{Co}^{2+}$ cations are located on both octahedral and tetrahedral lattice sites, resulting in a partially inverse structure with an inversion degree of $\gamma=0.76$, confirmed by magnetic measurements. This result is in good agreement with conventional preparation methods of $\mathrm{CoFe}_{2} \mathrm{O}_{4}$, stating the proposed postdeposition annealing treatment of $\mathrm{Fe}_{3} \mathrm{O}_{4} / \mathrm{CoO}$ bilayers on $\mathrm{SrTiO}_{3}(001)$ as a promising alternate pathway to prepare cobalt ferrite thin films.

\section{ACKNOWLEDGMENTS}

Financial support from the Deutsche Forschungsgemeinschaft (DFG under Grants No. KU2321/2-1, No. KU2321/61 , and No. WO533/20-1) is gratefully acknowledged. We thank Diamond Light Source for giving access to beamlines I07 (SI15334-1) and I09 (SI15205-1) and for the great beamline support. Additionally, we would like to acknowledge the assistance at beamline P09 at PETRA III (I-20170258), DESY, where parts of this work were carried out.
[1] V. A. M. Brabers, in Handbook of Magnetic Materials, edited by K. H. J. Buschow (Elsevier, 1995), Vol. 8.

[2] A. Hoffmann and S. D. Bader, Phys. Rev. Appl. 4, 047001 (2015)

[3] J. Cibert, J.-F. Bobo, and U. Lüders, C. R. Phys. 6, 977 (2005).

[4] J.-B. Moussy, J. Phys. D: Appl. Phys. 46, 143001 (2013).

[5] G. E. W. Bauer, E. Saitoh, and B. J. van Wees, Nat. Mater. 11, 391 (2012).

[6] S. M. Alshehri, A. N. Alhabarah, J. Ahmed, M. Naushad, and T. Ahamad, J. Colloid Interface Sci. 514, 1 (2018).

[7] V. Kashyap and S. Kurungot, ACS Catal. 8, 3715 (2018).

[8] V. S. Kumbhar, A. D. Jagadale, N. M. Shinde, and C. D. Lokhande, Appl. Surf. Sci. 259, 39 (2012).

[9] Z. H. Li, T. P. Zhao, X. Y. Zhan, D. S. Gao, Q. Z. Xiao, and G. T. Lei, Electrochim. Acta 55, 4594 (2010).

[10] Y.-Q. Chu, Z.-W. Fu, and Q.-Z. Qin, Electrochimica Acta 49, 4915 (2004).

[11] U. Lüders, A. Barthélémy, M. Bibes, K. Bouzehouane, S. Fusil, E. Jacquet, J.-P. Contour, J.-F. Bobo, J. Fontcuberta, and A. Fert, Adv. Mater. 18, 1733 (2006).

[12] S. Matzen, J.-B. Moussy, R. Mattana, K. Bouzehouane, C. Deranlot, and F. Petroff, Appl. Phys. Lett. 101, 042409 (2012).

[13] S. Matzen, J.-B. Moussy, P. Wei, C. Gatel, J. C. Cezar, and M. A. Arrio, Appl. Phys. Lett. 104, 182404 (2014).

[14] A. V. Ramos, M.-J. Guittet, J.-B. Moussy, R. Mattana, C. Deranlot, F. Petroff, and C. Gatel, Appl. Phys. Lett. 91, 122107 (2007).
[15] N.-T. H. Kim-Ngan, A. G. Balogh, J. D. Meyer, J. Brötz, M. Zając, T. Ślęzak, and J. Korecki, Surf. Sci. 603, 1175 (2009).

[16] K. A. Shaw, E. Lochner, and D. M. Lind, J. Appl. Phys. 87, 1727 (2000).

[17] N.-T. H. Kim-Ngan, A. G. Balogh, J. D. Meyer, J. Brötz, S. Hummelt, M. Zając, T. Ślęzak, and J. Korecki, Surf. Sci. 602, 2358 (2008).

[18] O. Kuschel, R. Buß, W. Spiess, T. Schemme, J. Wöllermann, K. Balinski, A. T. N'Diaye, T. Kuschel, J. Wollschläger, and K. Kuepper, Phys. Rev. B 94, 094423 (2016).

[19] C. Klewe, M. Meinert, A. Boehnke, K. Kuepper, E. Arenholz, A. Gupta, J.-M. Schmalhorst, T. Kuschel, and G. Reiss, J. Appl. Phys. 115, 123903 (2014).

[20] M. Hoppe, S. Döring, M. Gorgoi, S. Cramm, and M. Müller, Phys. Rev. B 91, 054418 (2015).

[21] O. Mauit, K. Fleischer, O. O'Dowd, D. Mullarkey, and I. V. Shvets, Thin Solid Films 612, 290 (2016).

[22] S. Seifikar, B. Calandro, E. Deeb, E. Sachet, J. Yang, J.-P. Maria, N. Bassiri-Gharb, and J. Schwartz, J. Appl. Phys. 112, 123910 (2012).

[23] S. Tanuma, C. J. Powell, and D. R. Penn, Surf. Interface Anal. 21, 165 (1994).

[24] R. Nakajima, J. Stöhr, and Y. U. Idzerda, Phys. Rev. B 59, 6421 (1999).

[25] S. Gota, M. Gautier-Soyer, and M. Sacchi, Phys. Rev. B 62, 4187 (2000). 
[26] A. Ruosi, C. Raisch, A. Verna, R. Werner, B. A. Davidson, J. Fujii, R. Kleiner, and D. Koelle, Phys. Rev. B 90, 125120 (2014).

[27] R. D. Cowan, The Theory of Atomic Structure and Spectra, 1st ed. (University of California Press, 1981).

[28] J. P. Crocombette, M. Pollak, F. Jollet, N. Thromat, and M. Gautier-Soyer, Phys. Rev. B 52, 3143 (1995).

[29] P. Kuiper, B. G. Searle, L.-C. Duda, R. M. Wolf, and P. J. van der Zaag, J. Electron Spectrosc. Relat. Phenom. 86, 107 (1997).

[30] E. Arenholz, G. van der Laan, R. V. Chopdekar, and Y. Suzuki, Phys. Rev. B 74, 094407 (2006).

[31] P. S. Miedema and F. M. F. de Groot, J. Electron Spectrosc. Relat. Phenom. 187, 32 (2013).

[32] K. Kuepper, O. Kuschel, N. Pathé, T. Schemme, J. Schmalhorst, A. Thomas, E. Arenholz, M. Gorgoi, R. Ovsyannikov, S. Bartkowski, G. Reiss, and J. Wollschläger, Phys. Rev. B 94, 024401 (2016).

[33] G. van der Laan, E. Arenholz, R. V. Chopdekar, and Y. Suzuki, Phys. Rev. B 77, 064407 (2008).

[34] S. Nappini, E. Magnano, F. Bondino, I. Pis, A. Barla, E. Fantechi, F. Pineider, C. Sangregorio, L. Vaccari, L. Venturelli, and P. Baglioni, J. Phys. Chem. C 119, 25529 (2015).

[35] J. Chen, D. J. Huang, A. Tanaka, C. F. Chang, S. C. Chung, W. B. Wu, and C. T. Chen, Phys. Rev. B 69, 085107 (2004).

[36] L. G. Parratt, Phys. Rev. 95, 359 (1954).

[37] L. Névot and P. Croce, Rev. Phys. Appl. 15, 761 (1980).

[38] See Supplemental Material at http://link.aps.org/supplemental/ 10.1103/PhysRevB.100.155418 for data of samples B and C and for CTM calculations of the Fe $L_{2,3}$ edge.

[39] T. Yamashita and P. Hayes, Appl. Surf. Sci. 254, 2441 (2008).

[40] T. Fujii, F. M. F. de Groot, G. A. Sawatzky, F. C. Voogt, T. Hibma, and K. Okada, Phys. Rev. B 59, 3195 (1999).

[41] S. A. Chambers, R. F. C. Farrow, S. Maat, M. F. Toney, L. Folks, J. G. Catalano, T. P. Trainor, and G. E. Brown, Jr., J. Magn. Magn. Mater. 246, 124 (2002).

[42] N. S. McIntyre and M. G. Cook, Anal. Chem. 47, 2208 (1975).

[43] T. J. Chuang, C. R. Brundle, and D. W. Rice, Surf. Sci. 59, 413 (1976).

[44] M. B. Trzhaskovskaya, V. I. Nefedov, and V. G. Yarzhemsky, At. Data Nucl. Data Tables 77, 97 (2001).

[45] M. B. Trzhaskovskaya, V. K. Nikulin, V. I. Nefedov, and V. G. Yarzhemsky, At. Data Nucl. Data Tables 92, 245 (2006).

[46] K. Kuepper, I. Balasz, H. Hesse, A. Winiarski, K. C. Prince, M. Matteucci, D. Wett, R. Szargan, E. Burzo, and M. Neumann, Phys. Status Solidi 201, 3252 (2004).

[47] P. Kuiper, B. G. Searle, P. Rudolf, L. H. Tjeng, and C. T. Chen, Phys. Rev. Lett. 70, 1549 (1993).

[48] J. A. Moyer, C. A. F. Vaz, E. Negusse, D. A. Arena, and V. E. Henrich, Phys. Rev. B 83, 035121 (2011).
[49] N. Daffe, F. Choueikani, S. Neveu, M.-A. Arrio, A. Juhin, P. Ohresser, V. Dupuis, and P. Sainctavit, J. Magn. Magn. Mater. 460, 243 (2018).

[50] F. M. F. de Groot, M. Abbate, J. van Elp, Y. J. Sawatzky, G. A. Ma, C. T. Chen, and F. Sette, J. Phys.: Condens. Matter 5, 2277 (1993).

[51] T. J. Regan, H. Ohldag, C. Stamm, F. Nolting, J. Lüning, J. Stöhr, and R. L. White, Phys. Rev. B 64, 214422 (2001).

[52] M. Saidani, W. Belkacem, and N. Mliki, J. Alloys Compd. 729, 1177 (2017).

[53] D. Carta, A. Casula, M. F. Falqui, D. Loche, G. Mountjoy, C. Sangregorio, and A. Corrias, J. Phys. Chem. C 113, 8606 (2009).

[54] D. Peddis, N. Yaacoub, M. Ferretti, A. Martinelli, G. Piccaluga, A. Musinu, C. Cannas, G. Navarra, J. M. Greneche, and D. Fiorani, J. Phys.: Condens. Matter 23, 426004 (2011).

[55] Y. Zhang, C. Deng, J. Ma, Y. Lin, and C.-W. Nan, Appl. Phys. Lett. 92, 062911 (2008).

[56] T. M. L. Alves, B. F. Amorim, M. A. M. Torres, C. G. Bezerra, S. N. Medeiros, P. L. Gastelois, L. E. F. Outon, and W. A. A. Macedo, RSC Adv. 7, 22187 (2017).

[57] S. Ammar, A. Helfen, N. Jouini, F. Fiévet, I. Rosenman, F. Villain, P. Molinié, and M. Danot, J. Mater. Chem. 11, 186 (2001).

[58] F. Rigato, J. Geshev, V. Skumryev, and J. Fontcuberta, J. Appl. Phys. 106, 113924 (2009).

[59] A. P. Roberts, Y. Cui, and K. L. Verosub, J. Geophys. Res.: Solid Earth 100, 17909 (1995).

[60] A. U. Rahman, M. A. Rafiq, K. Maaz, S. Karim, K. Hayat, and M. M. Hasan, J. Nanopart. Res. 16, 2476 (2014).

[61] E. O. Wollan and W. C. Koehler, Phys. Rev. 100, 545 (1955).

[62] V. N. Antonov, B. N. Harmon, and A. N. Yaresko, Phys. Rev. B 67, 024417 (2003).

[63] M. Pénicaud, B. Siberchicot, C. B. Sommers, and J. Kübler, J. Magn. Magn. Mater. 103, 212 (1992).

[64] H.-T. Jeng and G. Y. Guo, Phys. Rev. B 65, 094429 (2002).

[65] Z. Zhang and S. Satpathy, Phys. Rev. B 44, 13319 (1991).

[66] Z. Szotek, W. M. Temmerman, D. Ködderitzsch, A. Svane, L. Petit, and H. Winter, Phys. Rev. B 74, 174431 (2006).

[67] H.-T. Jeng and G. Y. Guo, J. Magn. Magn. Mater. 239, 88 (2002).

[68] B. S. Youmbi and F. Calvayrac, Surf. Sci. 621, 1 (2014).

[69] C. J. O'Brien, Z. Rak, and D. W. Brenner, J. Phys.: Condens. Matter 25, 445008 (2013).

[70] B. L. Henke, E. M. Gullikson, and J. C. Davis, At. Data. Nucl. Data Tables 54, 181 (1993).

[71] J. C. Slonczewski, Phys. Rev. 110, 1341 (1958).

[72] D. T. Margulies, F. T. Parker, M. L. Rudee, F. E. Spada, J. N. Chapman, P. R. Aitchison, and A. E. Berkowitz, Phys. Rev. Lett. 79, 5162 (1997). 